\title{
GPER mediates differential effects of estrogen on colon cancer cell proliferation and migration under normoxic and hypoxic conditions
}

\author{
Viviana Bustos ${ }^{1}$, Áine M. Nolan ${ }^{1}$, Anke Nijhuis ${ }^{2}$, Harry Harvey ${ }^{1}$, Alexandra Parker ${ }^{2}$, \\ Richard Poulsom², Jean McBryan ${ }^{1}$, Warren Thomas ${ }^{1}$, Andrew Silver ${ }^{2}$ and Brian J. \\ Harvey ${ }^{1}$ \\ ${ }^{1}$ Department of Molecular Medicine, Education and Research Centre, Beaumont Hospital, Royal College of Surgeons in \\ Ireland, Dublin, Ireland \\ ${ }^{2}$ Centre for Digestive Diseases, National Centre for Bowel Research and Surgical Innovation, Blizard Institute, Barts and The \\ London School of Medicine and Dentistry, London, UK
}

Correspondence to: Brian J. Harvey, email: brianharvey@rcsi.ie

Keywords: estrogen, GPER, VEGF, hypoxia, colorectal cancer

Received: March 29, $2017 \quad$ Accepted: July 26, $2017 \quad$ Published: September 06, 2017

Copyright: Bustos et al. This is an open-access article distributed under the terms of the Creative Commons Attribution License 3.0 (CC BY 3.0), which permits unrestricted use, distribution, and reproduction in any medium, provided the original author and source are credited.

\section{ABSTRACT}

The estrogen receptor ER $\beta$ is the predominant ER subtype expressed in normal well-differentiated colonic epithelium. However, ERß expression is lost under the hypoxic microenvironment as colorectal cancer (CRC) malignancy progresses. This raises questions about the role of signalling through other estrogen receptors such as ER $\alpha$ or G-protein coupled estrogen receptor (GPER, GPR30) by the estrogen $17 \beta$-estradiol (E2) under hypoxic conditions after ER $\beta$ is lost in CRC progression. We tested the hypothesis that E2 or hypoxia can act via GPER to contribute to the altered phenotype of CRC cells.

GPER expression was found to be up-regulated by hypoxia and $E 2$ in a panel of CRC cell lines. The E2-modulated gene, Ataxia telangiectasia mutated (ATM), was repressed in hypoxia via GPER signalling. E2 treatment enhanced hypoxia-induced expression of HIF1- $\alpha$ and VEGFA, but repressed HIF1- $\alpha$ and VEGFA expression under normoxic conditions. The expression and repression of VEGFA by E2 were mediated by a GPER-dependent mechanism. E2 treatment potentiated hypoxia-induced CRC cell migration and proliferation, whereas in normoxia, cell migration and proliferation were suppressed by $E 2$ treatment. The effects of E2 on these cellular responses in normoxia and hypoxia were mediated by GPER. In a cohort of 566 CRC patient tumor samples, GPER expression significantly associated with poor survival in CRC Stages 3-4 females but not in the stage-matched male population.

Our findings support a potentially pro-tumorigenic role for E2 in ERß-negative CRC under hypoxic conditions transduced via GPER and suggest a novel route of therapeutic intervention through GPER antagonism.

\section{INTRODUCTION}

A higher incidence of colorectal cancer (CRC) is found in males compared to females [1], and young women (18-44 years) with CRC have a better survival outcome compared to men of the same age [2] or to older women (over 50 years) [3]. These data suggest a protective role for the steroid hormone estrogen in CRC development. However, this premise remains controversial as recent epidemiological studies indicated that hormone replacement therapy (HRT) in post-menopausal women did not confer a protective effect $[4,5]$ in contrast to 
previous findings $[6,7]$. The role of estrogen and estrogen receptors in the onset and progression of CRC is not well understood. Estrogen may have a protective effect conferred through full-length ER $\beta$ (ER $\beta 1)$ expression [8]. ER $\beta 1$ is the predominant ER in the differentiated colonic epithelium and sustained ER $\beta 1$ expression in CRC correlates with better prognosis and patient survival. As the malignancy progresses ER $\beta 1$ is lost correlating with worse prognosis $[8,9]$. The relative expression levels of ER isoforms may complicate the interpretation of the Women's Health Initiative findings on protective/ exacerbating effects of estrogen in CRC [5, 7].

ER $\beta 1$ over-expression in CRC cells can also result in decreased cell migration [10], but whether estrogen can promote tumor progression following the loss of ER $\beta$ is unknown. E2-mediated promotion of tumor progression after ER $\beta$ loss may be through other estrogen-ligand receptors such as ER $\alpha$ or $G$ protein-coupled estrogen receptor (GPER, GPR30) activation, as has been reported in breast cancer [11].

The influence of the CRC tumor microenvironment on the tumorigenic role of estrogen is unknown. Hypoxic ( $\leq 3 \%$ oxygen) and anoxic $(\leq 0.3 \%$ oxygen) cancer cells display increased proliferation, increased angiogenesis and metastatic drive, and therapy resistance [12], due in part to the induction and activation of the hypoxia-inducible transcription factor HIF1- $\alpha$ [12]. In CRC, over-expression of HIF $1-\alpha$ and the HIF target vascular endothelial growth factor (VEGF), are independently associated with poor CRC patient survival $[13,14]$. Interestingly, GPER is a direct HIF 1- $\alpha$ target and is up-regulated following HIF stabilization in breast cancer cells [16].

Tumor cells show altered expression of key DNA damage repair genes such as ataxia telangiectasia mutated (ATM) [15], which drives the proliferation of genetically unstable tumor cells [16]. Loss of ATM expression is associated with poor survival in CRC [17]. In cervical cancer cells loss of ATM correlates with HIF expression [18]. An increase in phosphorylated ATM levels in hypoxic HCT116 colon cancer cells was described [19], but the modulation of ATM expression by low oxygen tension and the sensitivity of expression to E2, in CRC was not investigated. Hypoxia and estrogen are functionally equivalent in breast cancer cells [20] and E2 induces an increase in both HIFIA and VEGF gene expression $[21,22]$. In contrast, VEGF is repressed by ER $\beta 1$ over-expression in HT-29 colon cancer cells [23]. The induction and/or repression of ER $\alpha$ [24, 25], ER $\beta$ [24] and GPER [26] have also been reported in breast cancer cells. However, the functional consequences of E2 action within the hypoxic CRC cell micro-environment have not been investigated.

Here, we present novel insights into the protective or exacerbating effects of E2 on CRC tumor biology modulated by oxygen tension associated with the tumor microenvironment.

\section{RESULTS}

\section{HT-29 CRC cells are oxygen-sensitive}

We investigated whether CRC cell lines exhibit a typical HIF- $1 \alpha$ expression in response to low oxygen tension, including induction of HIF- $1 \alpha$-responsive genes such as VEGF [27]. In a panel of six CRC cell lines (colon cancer: HT-29, DLD-1, HT55, and HCT116; rectal cancer: C80 and C99), HIF-1 $\alpha$ and VEGF protein levels were detected in all cells cultured under hypoxic conditions ( $2 \%$ oxygen) for $24 \mathrm{~h}$ (Figure $1 \mathrm{~A}$ ), however the biggest response was observed in HT-29 cells and was used as the reference model in subsequent experiments. In the HT-29 colon cancer cells, hypoxia induced a 3-fold increase in HIF- $1 \alpha$ protein and mRNA expression with protein levels increasing after only 24 hours hypoxia (Figure 1B and 1C). VEGFA expression also increased at both the mRNA and protein levels, further confirming the hypoxic response of HT-29 cells to low oxygen tension (Figure 1D and 1E). HT-29 cells are recognised as a well-differentiated colon cancer cell line [28]. By comparison, HCT116 cells are poorly differentiated and DLD-1 colon cells have an intermediate phenotype [29] but their phenotypic responses to hypoxia are unknown. All three cell lines exhibited a hypoxic response to $24 \mathrm{~h}$ culture in $2 \%$ oxygen as evidenced by increases in HIF$1 \alpha$ and VEGFA protein expression (Figure 2A). HT-29 cells express high levels of E-cadherin and low levels of $\mathrm{N}$-cadherin and these differentiation characteristics were not affected by hypoxia (Figure 2B). In contrast, DLD-1 and HCT116 cells underwent de-differentiation in response to hypoxia, with increased $\mathrm{N}$-cadherin and decreased E-cadherin expression detectable following culture under hypoxic conditions (Figure 2B).

\section{Estrogen induces GPER expression in normoxia and hypoxia}

We were unable to detect ER $\alpha$ and ER $\beta$ mRNA expression in HT-29 cells (data not shown). Under normoxic conditions, HT-29 cells showed the highest basal expression of GPER under hypoxic conditions (Supplementary Figure 1B) and are thus the most relevant and suitable model to investigate the effects of GPER knock-down on function. The predicted molecular weight for GPER is $42 \mathrm{kDa}$, however, this refers to the purified recombinant GPER and not the endogenous protein expressed in cells which can undergo extensive glycosylation. Higher molecular weight sizes of GPER between 50 and $60 \mathrm{kDa}$ have been reported due to glycosylation and interaction with other proteins. We detected GPER as a strong band at $55 \mathrm{kDa}$ and have provided a control to show that this band is GPER by establishing knockdown cells using siRNA targeting 
GPER in which this band at $55 \mathrm{kDa}$ is lost (Figure 3 and Supplementary Figure 3).

Both the mRNA and protein levels of GPER were increased in response to $24 \mathrm{~h}$ estrogen treatment (Figure 3A and 3C). Under hypoxic conditions, GPER expression was increased in HT-29 cells and was notably higher than GPER expression in other CRC cell lines (Supplementary Figure 1). Estrogen treatment under hypoxic conditions produced a similar response as was observed under normoxia with increases in both mRNA and protein expression of GPER (Figure 3). A siRNA targeting GPER was used successfully to decrease the mRNA and protein expression of GPER (Figure 3). In the presence of this siRNA, estrogen failed to increase GPER protein expression significantly under normoxic or hypoxic conditions (Figure 3A-3D).

A
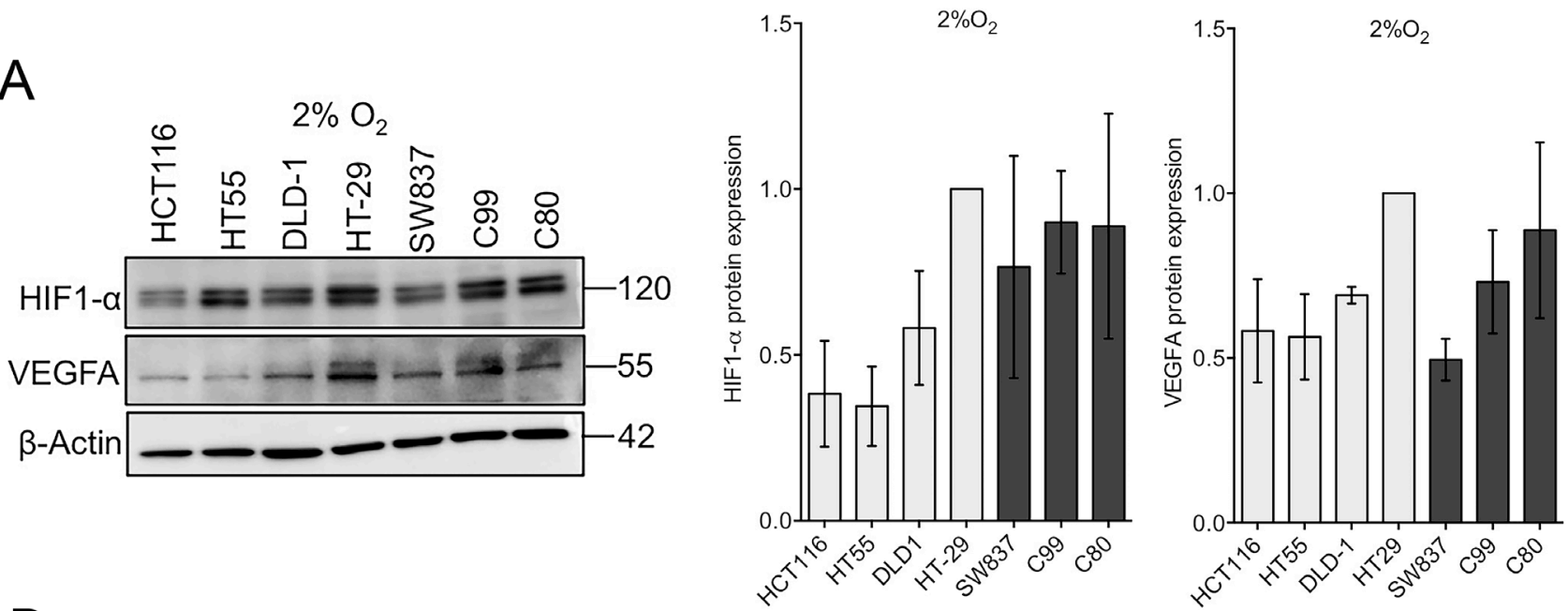

B

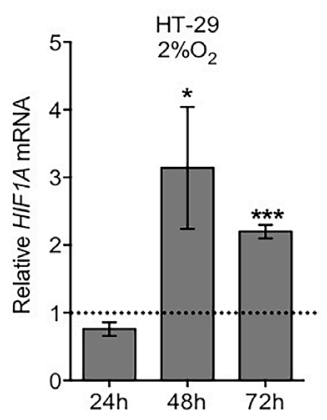

C
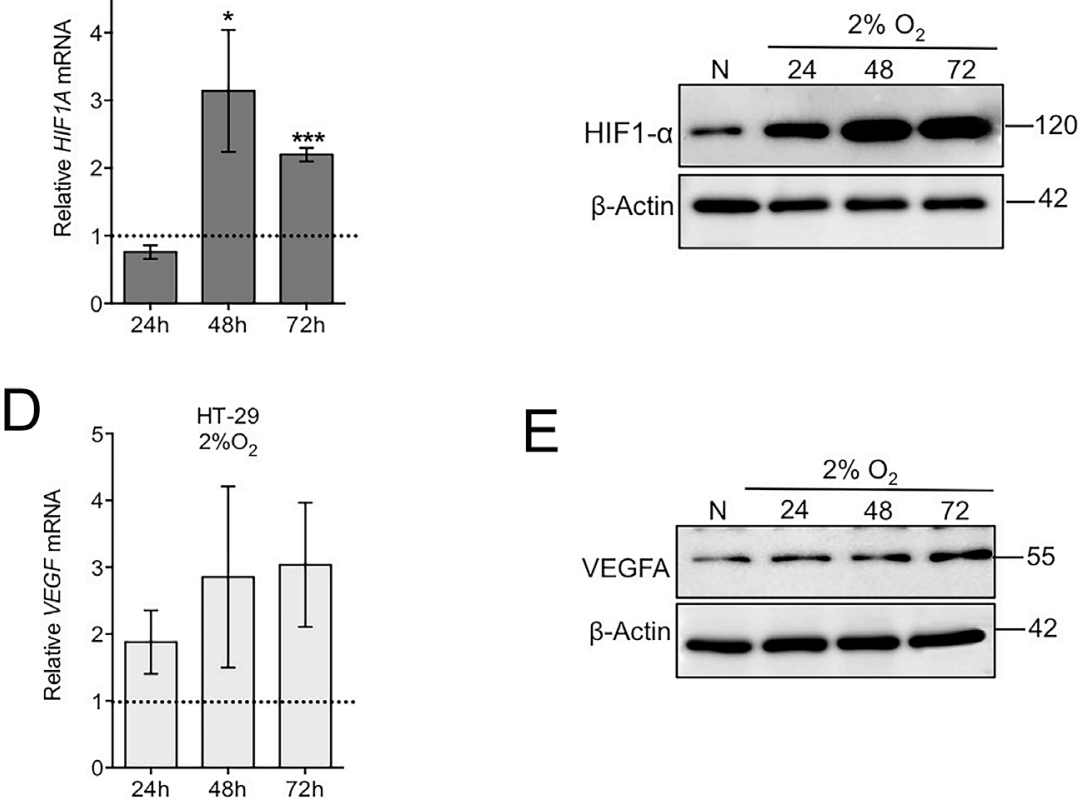

$E$

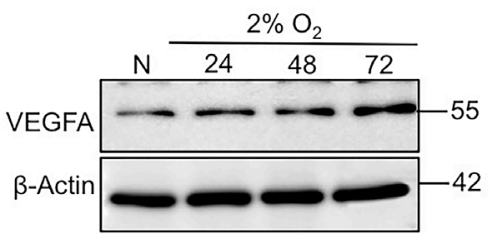

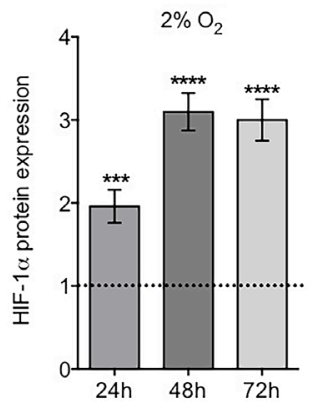

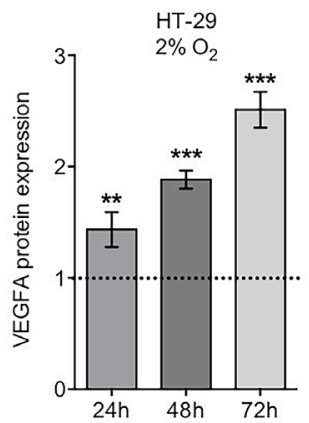

Figure 1: Hypoxic sensitivity of colorectal cancer cell lines. (A) Western blot and densitometry analysis of HIF1- $\alpha$ and VEGFA protein expression in a panel of colon (HCT116, HT55, DLD-1 and HT-29) and rectal (SW837, C99 and C80) cancer cell lines cultured in $2 \%$ oxygen for $24 \mathrm{~h}$. $\mathrm{n}=4$, error bars represent SEM. (B) Time course of HIF1A mRNA expression in HT-29 colon cancer cells in response to culturing in $2 \%$ oxygen for 24,48 and $72 \mathrm{~h}$. The dotted line represents basal expression under normoxic conditions. Mean $\pm \mathrm{SEM}, \mathrm{n}=3$ 4. (C) Western blot and densitometry analysis of HIF1- $\alpha$ protein expression in response to hypoxic culture. Mean \pm SEM, $n=4$. (D) Time course of $V E G F$ mRNA expression in HT-29 cells under hypoxic conditions. The dotted line represents basal expression under normoxic conditions. Mean \pm SEM, $n=3-4$. (E) Western blot and densitometry analysis of VEGFA protein expression in response to hypoxic culture. Mean \pm SEM, $\mathrm{n}=4$. mRNA levels were normalized to $P P I B$ endogenous control. $\beta$-actin was used as a loading control for protein. ${ }^{*} P<0.05$, ${ }^{* *} P<0.01,{ }^{* * *} P<0.001,{ }^{* * * *} P<0.0001$. $P$-values relative to normoxic controls. 


\section{Estrogen suppresses ATM expression via GPER in normoxia and hypoxia}

The DNA repair gene $A T M$ has been associated with a protective effect in CRC and loss of ATM has been correlated with poor outcome in CRC patients [21]. To investigate the impact of estrogen on ATM expression, HT-29, DLD-1 and HCT116 cells were treated with estrogen for $24 \mathrm{~h}$ under normoxic conditions. Estrogen repressed ATM protein expression in both HT-29 and DLD-1 cells significantly, but not in the less differentiated HCT116 cells (Figure 4A). Moreover, the repression of ATM caused by estrogen in HT-29 cells was confirmed to be via GPER as siRNA targeting GPER silenced the estrogenic effects on ATM expression at both the mRNA and protein levels (Figure 4B and 4D). Hypoxia also induced repression of ATM in HT-29 and DLD-1 cells (Supplementary Figure 2A). Under hypoxic conditions, estrogen further suppressed ATM expression and this was confirmed to involve a GPER-dependent mechanism since the ATM response to estrogen was lost in GPERsilenced cells (Figure 4C and 4E). The GPER agonist G1 also produced a decrease in ATM mRNA expression under normoxic conditions (Supplementary Figure 2B).

\section{Estrogen, acting via GPER, differentially regulates VEGFA and HIF-1 $\alpha$ in normoxia and hypoxia}

Over-expression of VEGFA and HIF-1 $\alpha$ are independently associated with poor outcome in CRC $[13,14]$. In normoxic HT-29 cells, estrogen treatment

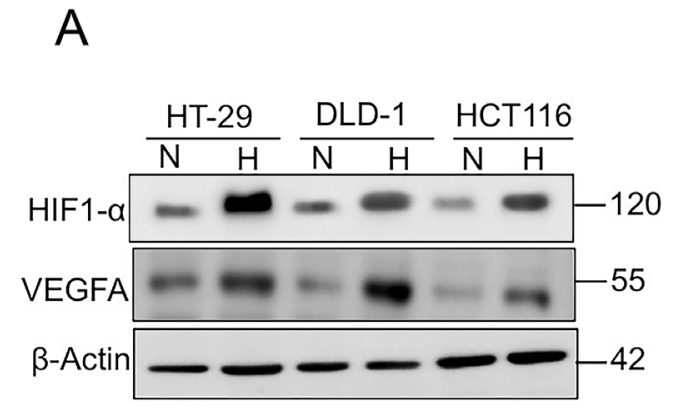

B

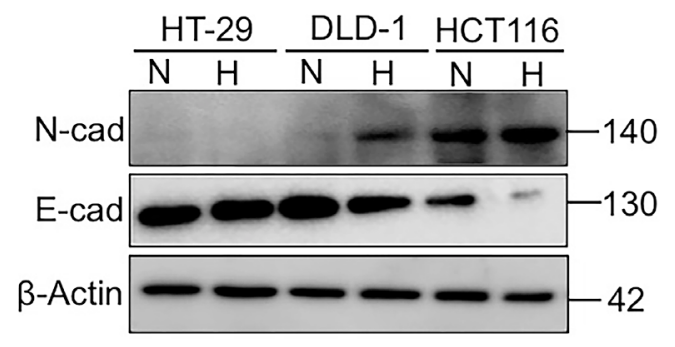

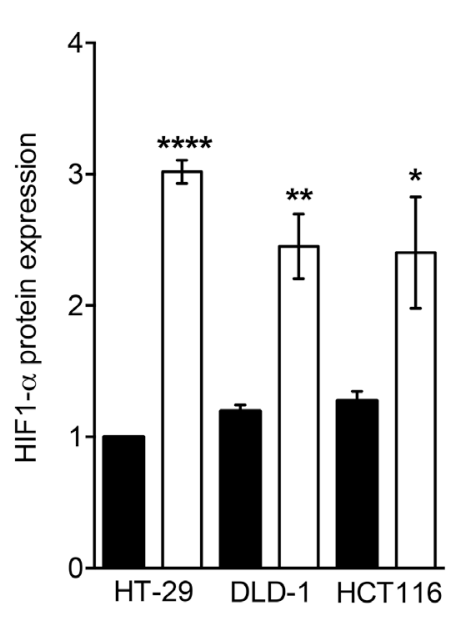
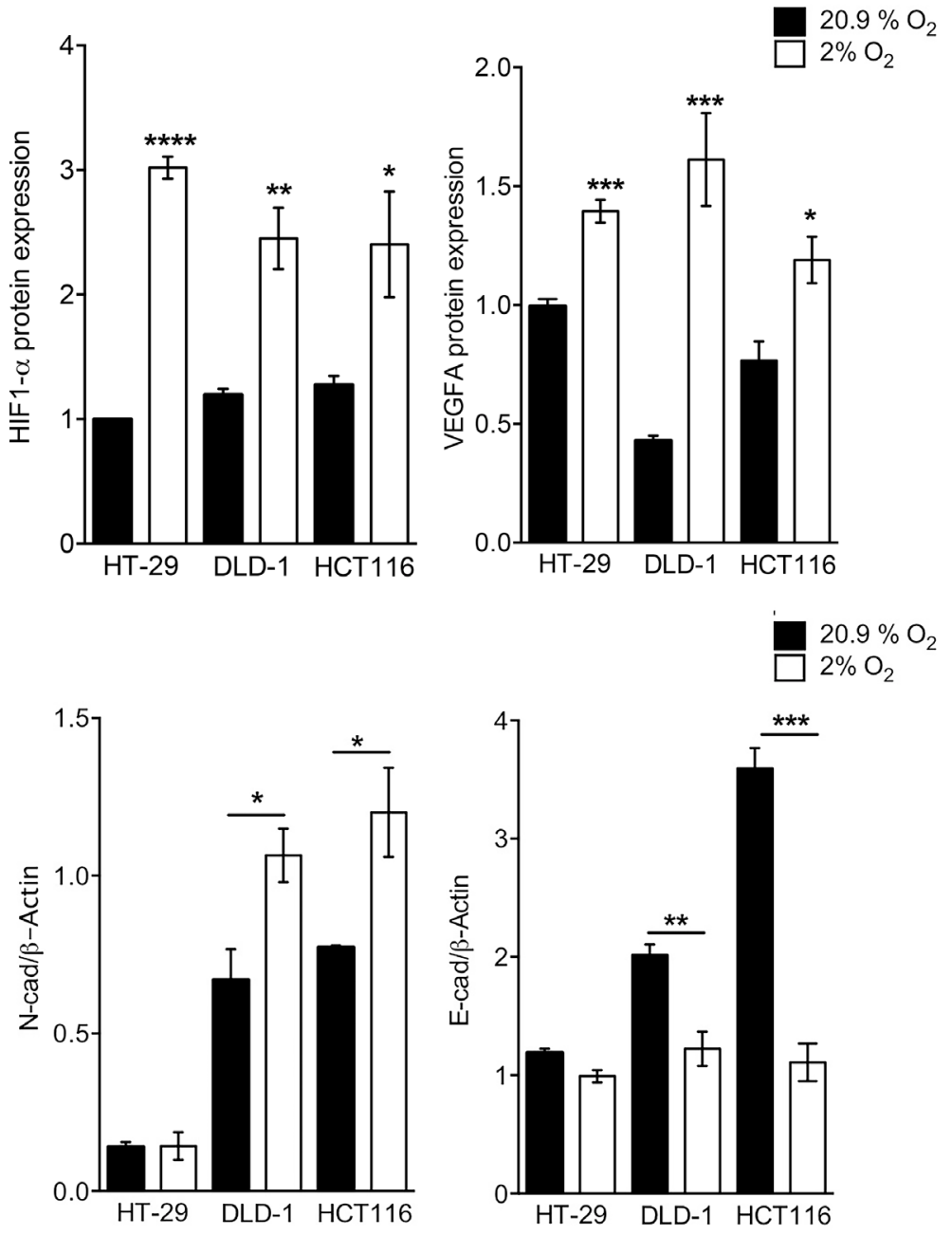

Figure 2: Hypoxic effects on differentiation status of colon cancer cells. (A) Western blot and densitometry analysis showing increased HIF1- $\alpha$ and VEGFA protein following $24 \mathrm{~h}$ culture in hypoxia $(\mathrm{H})$ compared to normoxia $(\mathrm{N})$ in a panel of colon cancer cell lines (HT-29, DLD-1 and HCT116). $\beta$-actin was used as a loading control. Expression was normalised to the protein expression under normoxic conditions in HT-29 cell line. Mean \pm SEM, $\mathrm{n}=4-5{ }^{* *} P<0.001,{ }^{* * *} P<0.0001,{ }^{* * * *} P<0.00001$. (B) Western blot and densitometry analysis of E-cadherin and $\mathrm{N}$-cadherin protein expression. Hypoxia promotes $\mathrm{N}$-cadherin and further suppresses E-cadherin expression in cells exhibiting a moderately and less differentiated epithelial phenotype (DLD-1 and HCT116 respectively). HT-29 cells display an epithelial phenotype in both normoxia and hypoxia. Mean \pm SEM, n $=4 .{ }^{*} P<0.01,{ }^{* *} P<0.001,{ }^{* * *} P<0.0001$. 
A

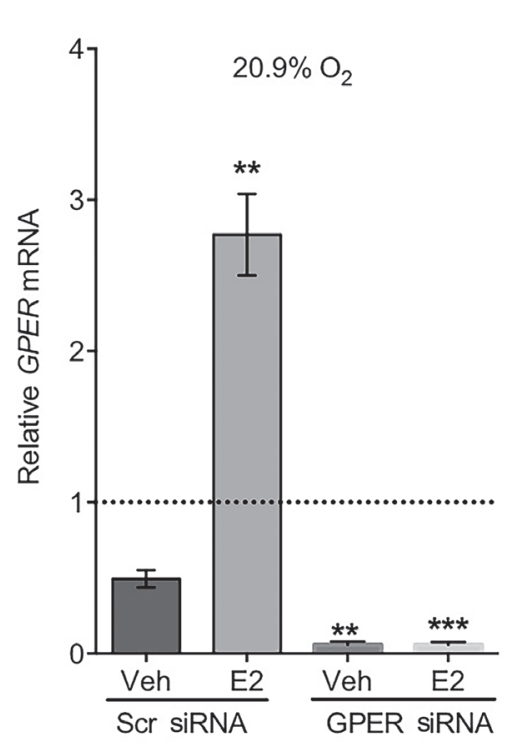

C

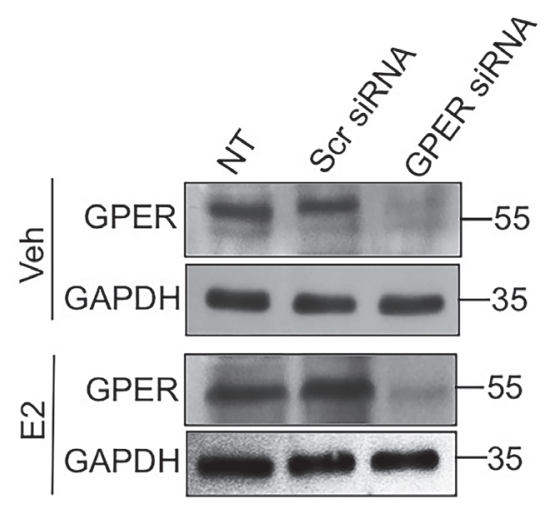

D

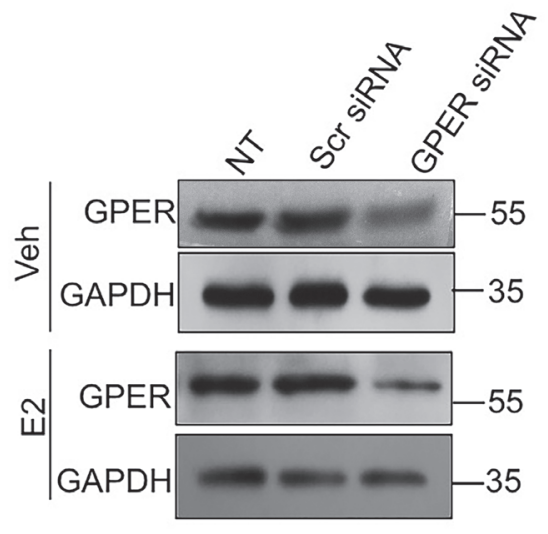

B
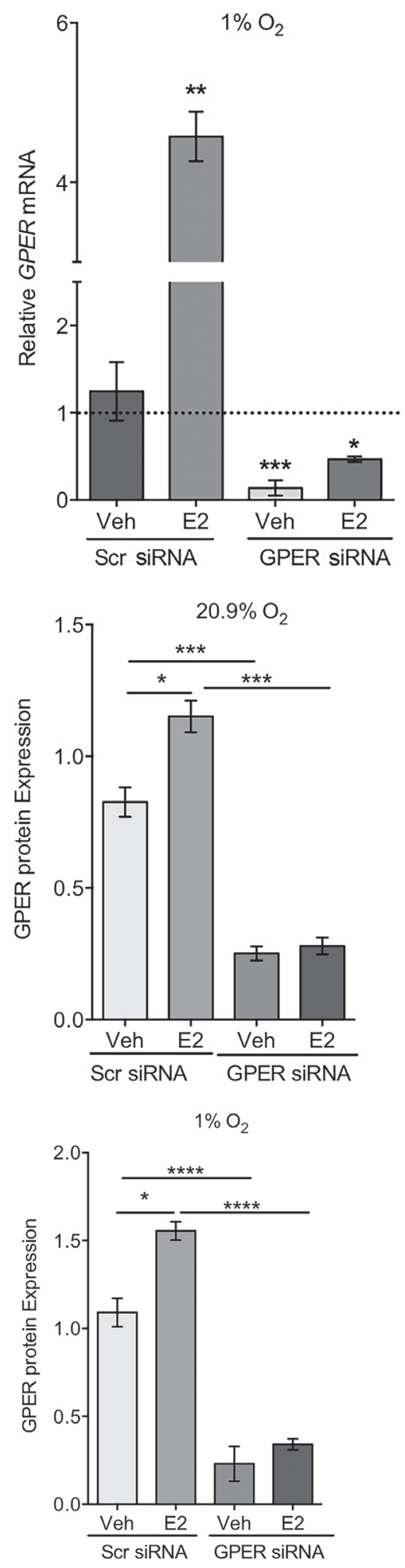

Figure 3: Estrogen increases GPER expression in normoxia and hypoxia. (A, B) Real-time PCR analysis of GPER mRNA expression normalised to $18 \mathrm{~S}$ rRNA in transfected HT-29 cells treated with ethanol (Veh) or 10nM Estradiol (E2) for 24h. The experiment was conducted under normoxic (A) and hypoxic (B) conditions. Cells were transfected with either scrambled control (Scr) or GPERtargeting siRNA. The dotted line represents basal expression in non-transfected, untreated cells. (Mean $\pm \mathrm{SEM}, \mathrm{n}=3$ ). P-values are relative to the Veh Scr siRNA control. ${ }^{*} P<0.05,{ }^{* * *} P<0.01,{ }^{* * * *} P<0.001$. (C, D) Western blot and densitometry analysis of GPER protein expression, normalised to GAPDH, in transfected HT-29 cells treated with ethanol (Veh) or 10nM Estradiol for 24h. The experiment was conducted under normoxic (C) and hypoxic (D) conditions. Mean \pm SEM, $\mathrm{n}=4 .{ }^{*} P<0.01,{ }^{* * *} P<0.001,{ }^{* * * *} P<0.0001$. 

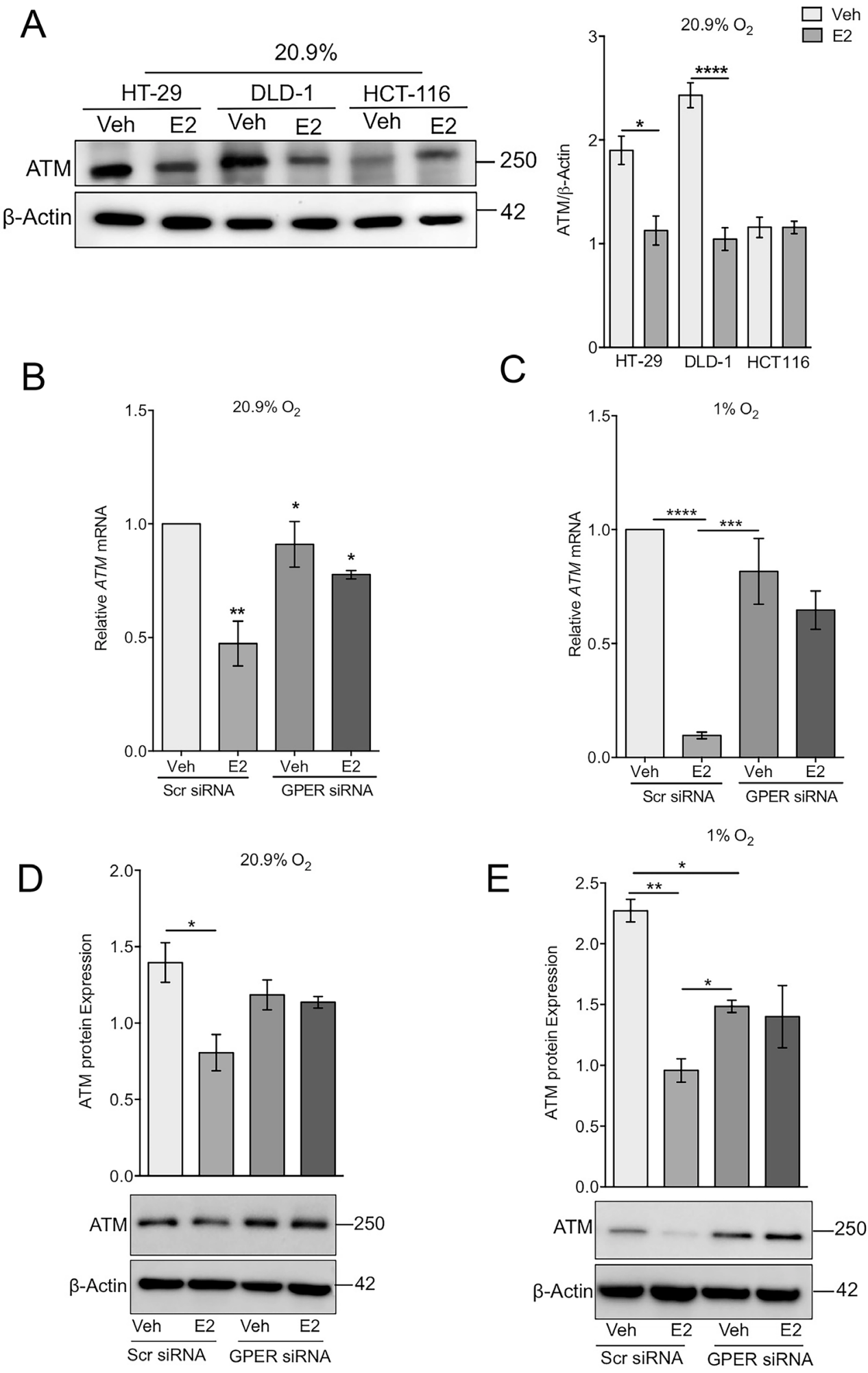

Figure 4: GPER-dependent regulation of ATM expression by estrogen. (A) Western blot and densitometry analysis of ATM protein expression in a panel of cell lines (HT-29, DLD-1 and HCT116) treated with ethanol control (Veh) or 10nM estradiol (E2) under normoxic conditions. $\beta$-actin was used as a loading control, mean \pm SEM, $\mathrm{n}=4,{ }^{*} P<0.01,{ }^{* * * *} P<0.0001$. (B, C) Real-time PCR analysis of ATM mRNA normalised to 18S rRNA in HT-29 cells transfected with scrambled siRNA (Scr) or GPER Silencer selected RNA (GPER siRNA). Cells were treated with ethanol (Veh) or $10 \mathrm{nM}$ estradiol (E2) for $24 \mathrm{~h}$. Cells were cultured in either normoxic conditions (B) or with $2 \%$ oxygen $(\mathrm{C})$. Mean $\pm \mathrm{SEM}, \mathrm{n}=4$, P-values are relative to normoxic vehicle treated conditions, ${ }^{*} P<0.05,{ }^{* *} P<0.01$, ${ }^{* * *} P<0.001$ ${ }^{* * * *} \mathrm{P}<0.0001$. (D, E) Western blot and densitometry of ATM protein expression from the same experiments conducted in (B) and (C). Mean \pm SEM, $\mathrm{n}=4,{ }^{*} P<0.05,{ }^{* *} P<0.01$. 
suppressed VEGFA and HIF-1 $\alpha$ expression (Figure 5A and Figure 6). The regulation of VEGFA was confirmed to be dependent on GPER since the suppression of VEGFA by estrogen was diminished in GPER-silenced cells (Figure 5B). However, in stark contrast, under hypoxic conditions, estrogen increased VEGFA expression at both the mRNA and protein levels (Figure 5C and 5D). Moreover, a GPER-dependence of the stimulatory effects of estrogen on VEGFA was observed under hypoxic conditions (Figure 5E). Estrogen also significantly increased HIF-1 $\alpha$ protein levels under hypoxic conditions at the $24 \mathrm{~h}$ time point examined (Figure 6). This is a novel finding whereby estrogen, acting through GPER, can produce potentially tumor-suppressing effects in normoxia but opposing, tumor-promoting effects under hypoxic conditions and may offer a molecular mechanism to explain the apparent contradictory observations in patient studies on sexual dimorphism and estrogen protection/exacerbation in CRC. If the oxygen tension in the tumor microenvironment can modulate the estrogen effects on GPER and VEGF this could provide a mechanism for opposing effects of estrogen depending on the CRC stage and the site of sampling from tumor biopsies.

\section{Estrogen, acting via GPER, suppresses migration in normoxia but enhances it in hypoxia}

To investigate if estrogen and GPER have functional roles to play in CRC cells, two types of migration assay were used. Both the scratch wound and Boyden chamber assays produced the same pattern of estrogen modulation of CRC cell migration - stimulation under hypoxic conditions and inhibition of migration under normoxic conditions in HT-29 (Figure 7) and DLD-1 (Figure 8) CRC cells. Under normoxic conditions, estrogen, or the GPER-selective agonist G1, reduced cell migration. Consistent with this, G15, an antagonist of GPER, enhanced migration of both HT-29 and DLD-1 CRC cells and limited the estrogenic suppression of migration (Figure 7 and Figure 8).

Basal levels of migration were significantly enhanced in both HT-29 and DLD-1 cells under hypoxic compared to normoxic conditions (Figure 7 and Figure $8)$. In contrast to the normoxic response, both estrogen and G1 enhanced cell migration in hypoxic conditions. This response was inhibited by the GPER antagonist G15 (Figure 7 and Figure 8). Thus, the protective effect of reduced migration with estrogen in normoxia was lost under reduced oxygen conditions.

To further confirm the involvement of GPER in the cell migration responses to estrogen, the Boyden chamber assay was repeated using siRNA knock-down of GPER (Figure 9 and Supplementary Figure 3). The silencing of GPER expression led to significantly enhanced basal migration under normoxic conditions and reduced migration under hypoxic conditions in HT-29 cells (Figure
9A and 9B) and in DLD-1 cells (Figure 9C and 9D). Under normoxic conditions the ability of estrogen and G1 to retard cell migration was lost in GPER-silenced cells (Figure 9A and 9C). Conversely, the effects of estrogen and G1 to increase cell migration in hypoxia were lost in GPER-silenced cells (Figure 9B and 9D).

\section{Estrogen, acting via GPER, suppresses proliferation in normoxia but enhances it in hypoxia}

To further explore the pro- and anti-tumorigenic potential of estrogen, proliferation assays were conducted with HT-29 (slow proliferative phenotype) and DLD-1 cells (fast proliferative phenotype) (Figure 10). Under normoxic conditions, estrogen and G1 both suppressed proliferation (Figure 10A and 10B). Under hypoxic conditions, the estrogenic signal produced the opposite functional effect with both estrogen and G1 enhancing proliferation and G15 inhibiting proliferation (Figure 10A and 10B). Under both normoxic and hypoxic conditions, the knock-down of GPER expression using siRNA prevented estrogen and G1 from altering cell proliferation rates (Figure 10C-10F). Thus, GPER is essential in transducing the normoxic anti-proliferative effects of estrogen as well as the hypoxic proliferative effects of estrogen.

\section{GPER expression is associated with poor CRC patient outcome}

The potential clinical relevance of GPER was analysed by Kaplan Meier analysis of a published microarray data set of 566 patients. Substratification of tumors based on patient gender and tumor stage at diagnosis was also carried out. Using a median cutoff, high expression of GPER significantly associated with poor relapse free survival in women with stages 3 and $4 \mathrm{CRC}(\mathrm{P}=0.022$, Figure $11 \mathrm{~B})$. Of note, there was no significant difference in survival for male or female patients with stage 1 or 2 CRC based on GPER expression (Figure 11A and 11C). Interestingly, male patients with stage 3 or 4 CRC showed no survival difference based on GPER expression (Figure 9D). This patient data indicates a sexual dimorphism of GPER role in CRC progression and survival and is consistent with our in vitro studies demonstrating a pro-tumorigenic role for estrogen, acting via GPER, in a hypoxic environment.

\section{DISCUSSION}

This study presents the first analysis of combined estrogen and hypoxia-mediated effects in variously differentiated CRC cell lines. In particular, we have focused on the regulation of pro-angiogenic HIF $1-\alpha$ and VEGFA expression and the regulation of the DNA repair 
A
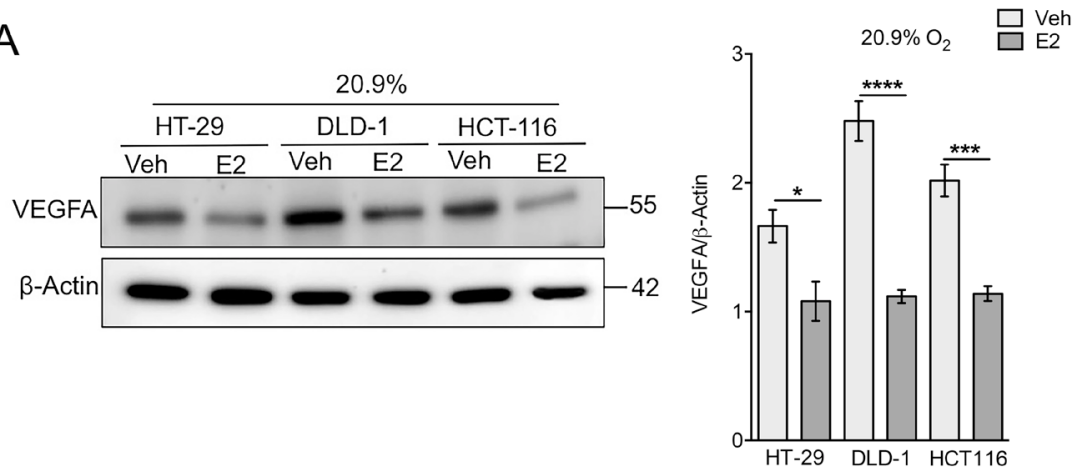

B

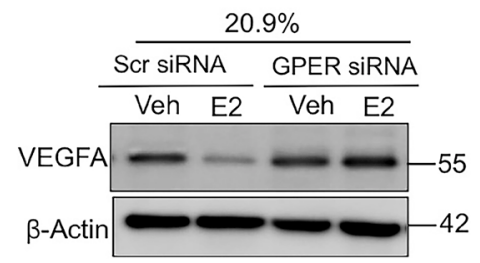

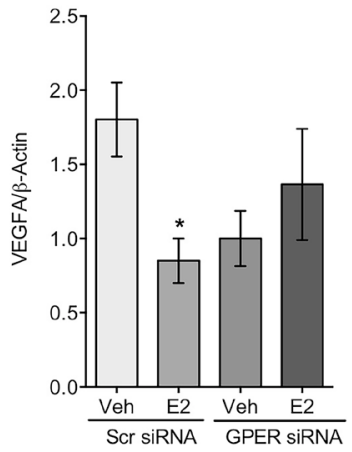

C
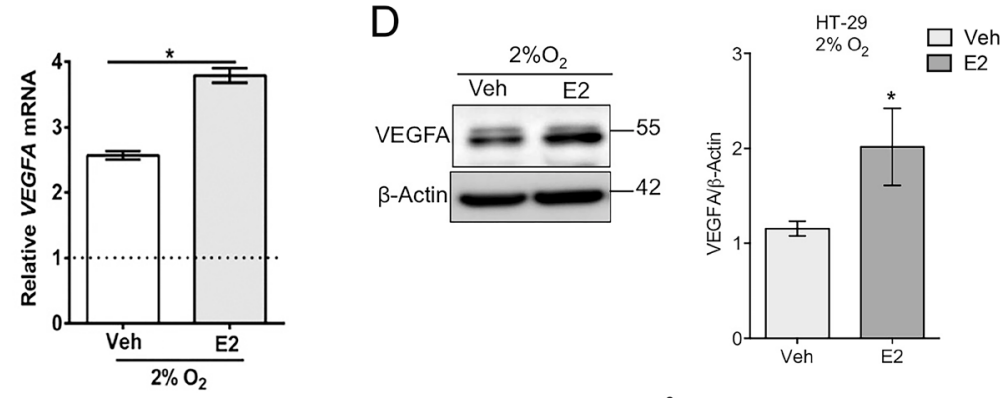

E
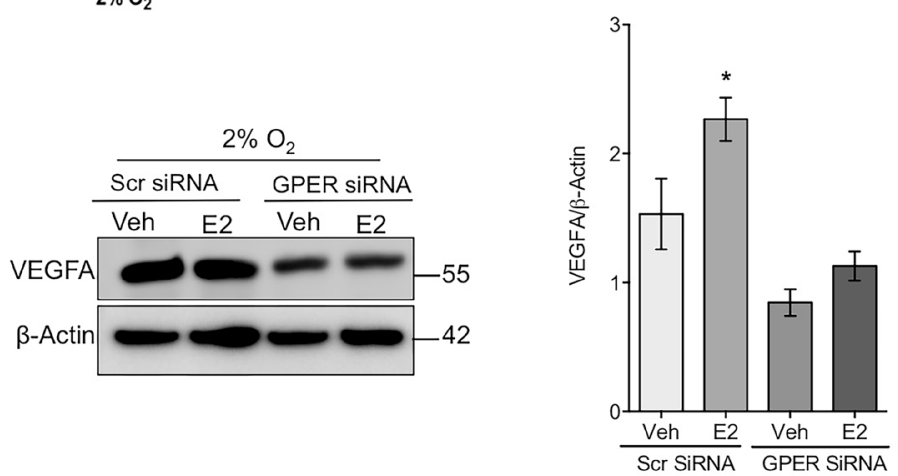

Figure 5: GPER- and oxygen-dependent regulation of VEGF expression by estrogen. (A) Western blot and densitometry analysis of VEGFA protein expression in a panel of cell lines (HT-29, DLD-1 and HCT116) treated with ethanol control (Veh) or 10nM estradiol (E2) under normoxic conditions. $\beta$-actin was used as a loading control. Mean \pm SEM, $\mathrm{n}=4,{ }^{*} P<0.01,{ }^{* * *} P<0.001,{ }^{* * * *} P<0.0001$, p-values relative to vehicle treated controls. (B) Western blot and densitometry of VEGFA protein expression in normoxic transfected HT-29 cells treated with vehicle or estradiol. Scrambled control (Scr) or GPER-targeting siRNA were used. Mean $\pm \mathrm{SEM}, \mathrm{n}=4,{ }^{*} P<0.05$, p-value relative to vehicle treated control. (C) VEGF mRNA expression normalised to PPIB endogenous control in HT-29 cells treated with ethanol (Vehicle) or 10nM estradiol (E2) under hypoxic conditions $\left(2 \% \mathrm{O}_{2}\right)$. Dotted line represents vehicle-treated normoxic HT-29 cells. Mean \pm SEM, $n=3,{ }^{*} P<0.01$, p-value relative to vehicle treated control. (D) Western blot and densitometry analysis of VEGF protein expression in hypoxic HT-29 cells treated with ethanol (Veh) or 10nM estradiol (E2). $\beta$-actin was used as a loading control, mean \pm SEM, $\mathrm{n}=5{ }^{*} P<0.05$. p-value relative to vehicle treated control. (E) Western blot and densitometry of VEGFA protein expression in hypoxic transfected HT-29 cells treated with vehicle or estradiol. Scrambled control (Scr) or GPER-targeting siRNA were used. Mean \pm SEM, $\mathrm{n}=5$ ${ }^{*} P<0.05$. P-value relative to vehicle Scr treated control. 
gene $A T M$. Our data demonstrates that E2, acting through GPER, up-regulates HIF $1-\alpha$ and VEGFA expression and promotes proliferation and migration of CRC cells under hypoxic conditions. This finding identifies a potentially pro-tumorigenic role for E2 in the hypoxic environment of ER-negative colorectal tumors.

Previous studies in breast cancer cells showed that estradiol induces the expression of $H I F 1 A$, which is involved in the transcriptional regulation of VEGF [30, 31]. We tested this relationship in a panel of CRC cell lines. Here we show that in normoxic colorectal cancer cells, E2 can repress HIF1- $\alpha$ and VEGFA expression. By contrast, in hypoxic CRC cells, E2 potentiated the hypoxia-induced HIF $1-\alpha$ and VEGFA expression. Thus estrogenic responses appear to be both cell type-specific and dependent on the cellular hypoxic microenvironment. Moreover, our results corroborate previous studies in hypoxic embryonic cells [31], where $H I F 1 A$ mediates transcriptional activation of the $V E G F$ gene and E2 enhances the expression of $H I F 1 A$ and $V E G F$.
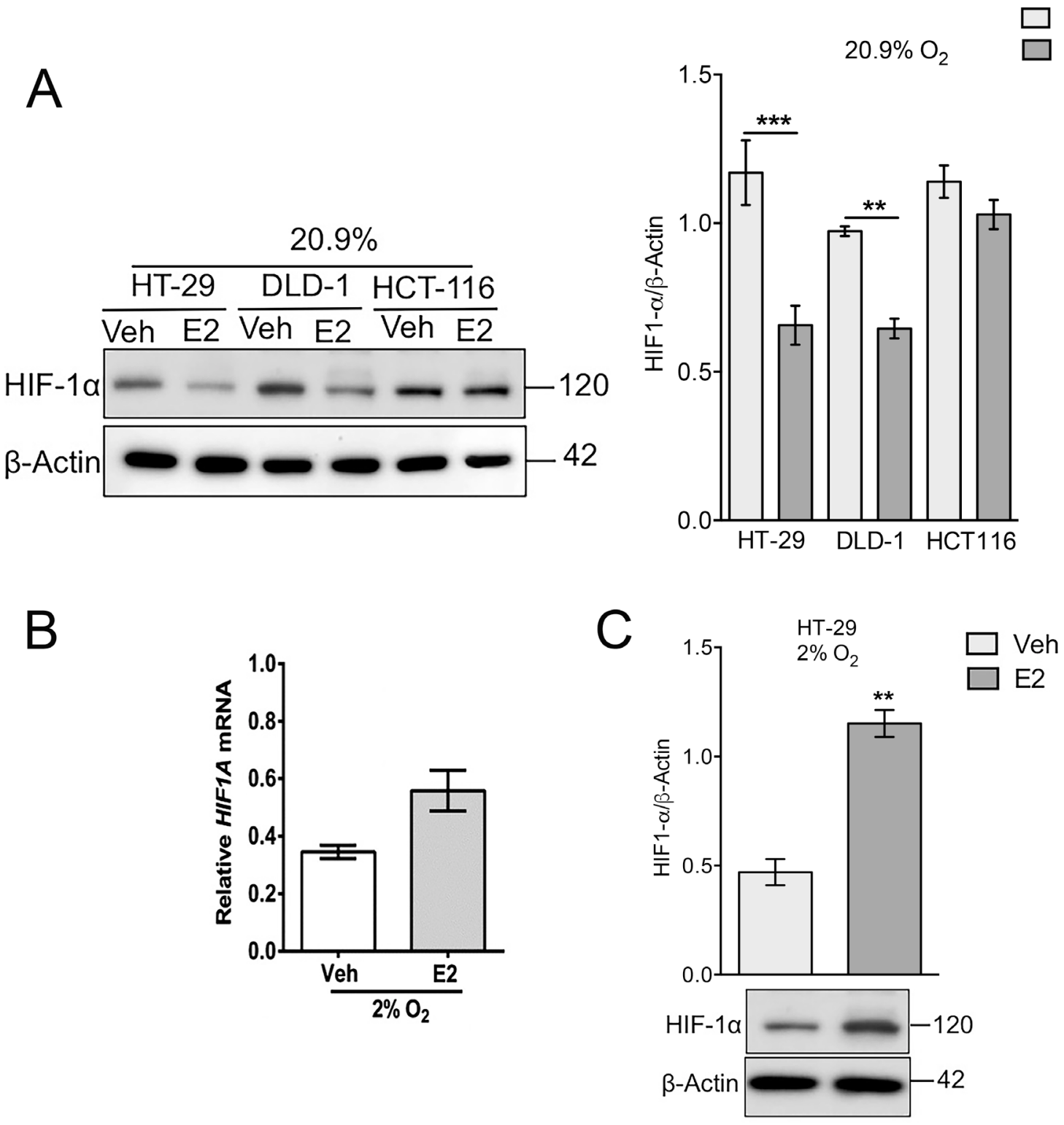

Figure 6: Oxygen tension and estradiol modulate HIF1- $\alpha$ expression in colon cancer cells. (A) Western blot and densitometry analysis of HIF1- $\alpha$ protein expression in a panel of cell lines (HT-29, DLD-1 and HCT116) treated with ethanol control (Veh) or 10nM estradiol (E2) under normoxic $\left(20.9 \% \mathrm{O}_{2}\right)$ conditions. $\beta$-actin was used as a loading control. Mean $\pm \mathrm{SEM}, \mathrm{n}=4,{ }^{*} P<0.01,{ }^{* * *} P<0.001$, p-values relative to vehicle treated controls. (B) HIF1A mRNA expression normalised to PPIB endogenous control in HT-29 cells treated with ethanol (Veh) or 10nM estradiol (E2) under hypoxic conditions $\left(2 \% \mathrm{O}_{2}\right)$. Dotted line represents vehicle-treated normoxic HT-29 cells. Mean \pm SEM, $n=3$. (C) Western blot and densitometry analysis of HIF1- $\alpha$ protein expression in hypoxic HT-29 cells treated with ethanol (Veh) or $10 \mathrm{nM}$ estradiol (E2). $\beta$-actin was used as a loading control, mean $\pm \mathrm{SEM}, \mathrm{n}=4{ }^{*} P<0.05$. P-value relative to vehicle treated control. 
A
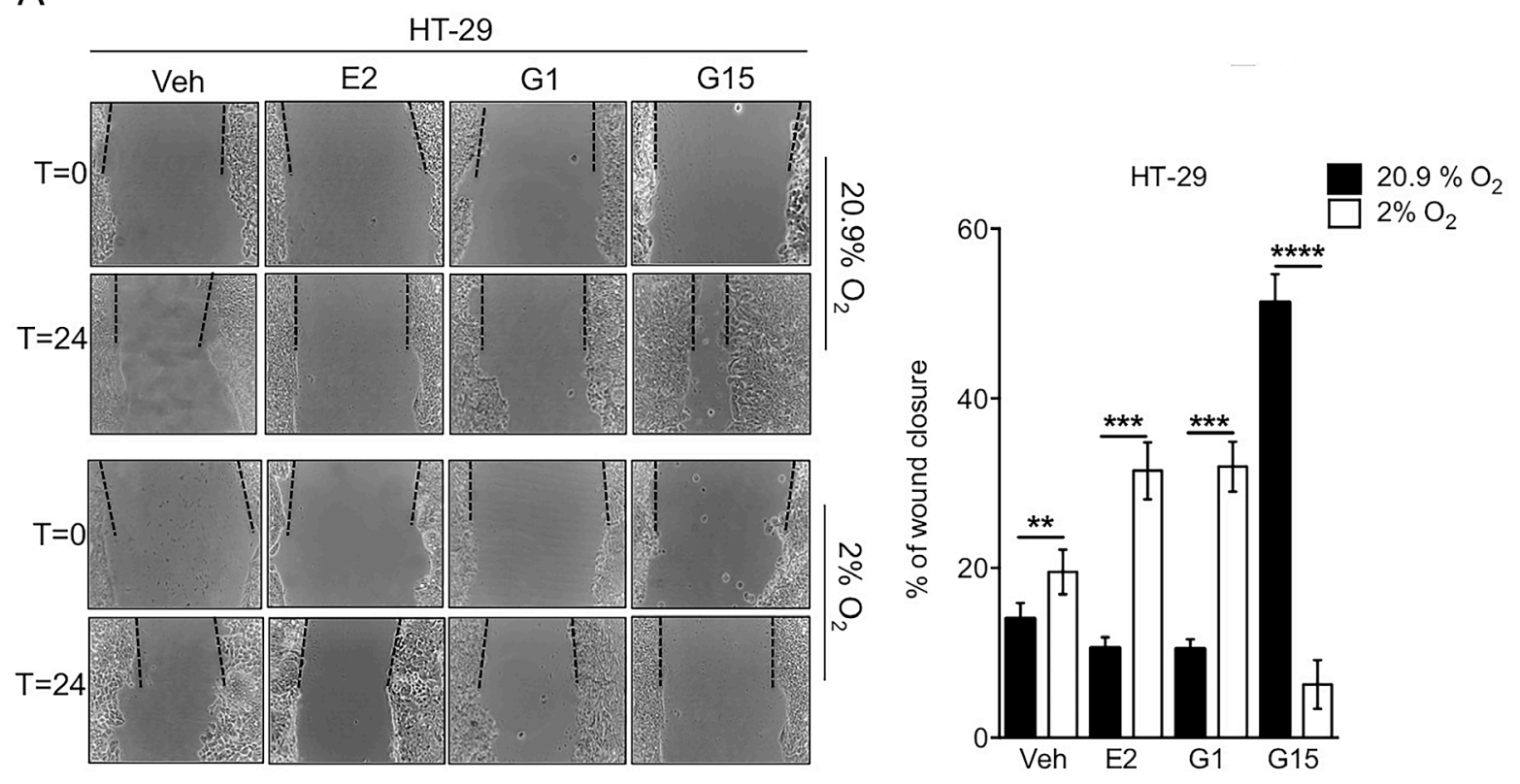

B
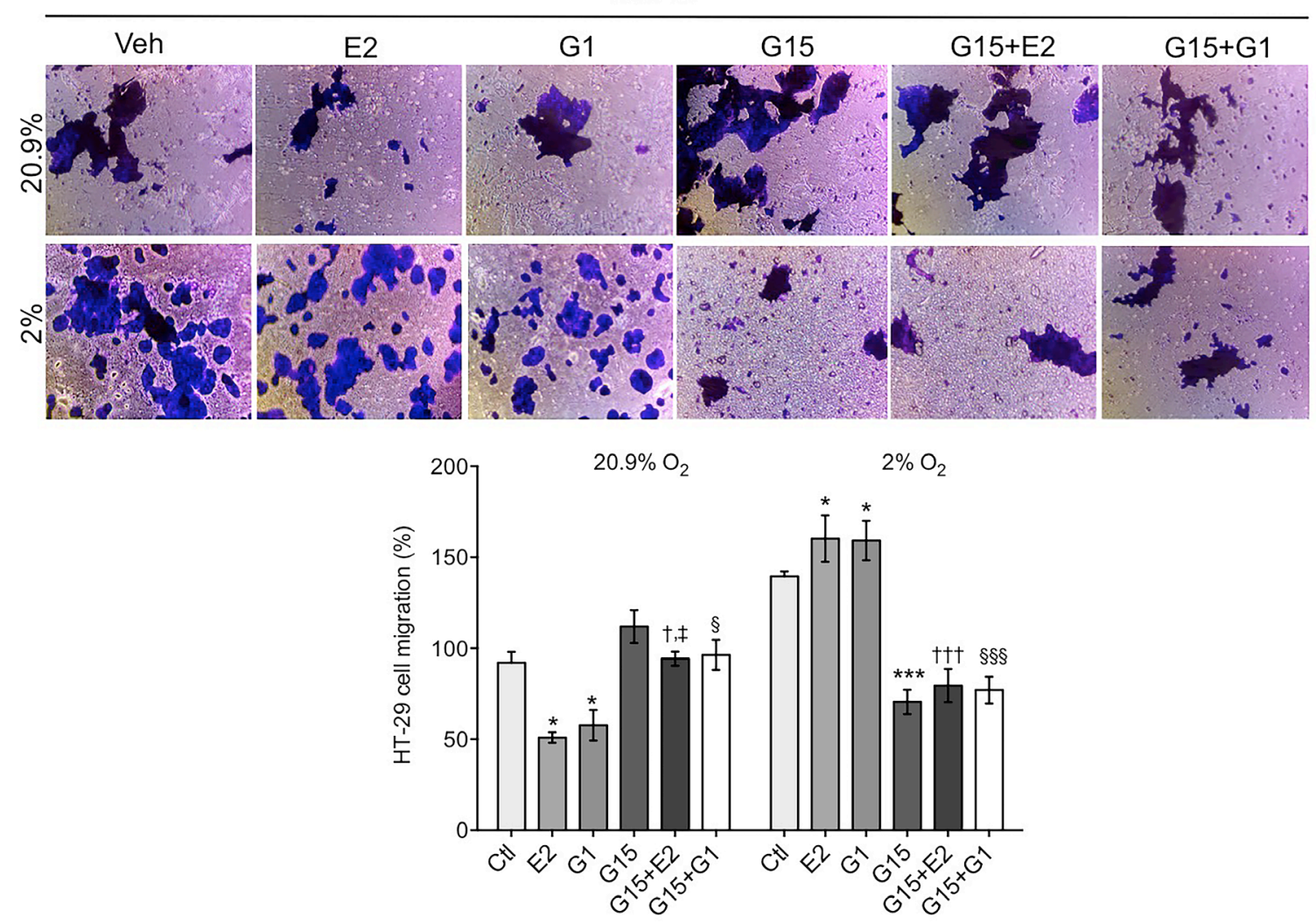

Figure 7: Oxygen-dependent regulation of migration by estrogen in HT-29 cells. (A) Wound healing assay in HT-29 cells under normoxic $\left(20.9 \% \mathrm{O}_{2}\right)$ and hypoxic $\left(2 \% \mathrm{O}_{2}\right)$ conditions. Representative images are shown of the scratches at time 0 and following $24 \mathrm{~h}$. Dashed lines indicate wound margins. Graph shows the \% wound closure under each condition. Cells were treated with $10 \mathrm{nM}$ estradiol (E2), $1 \mu \mathrm{M}$ G1 (a GPER-selective agonist) or $5 \mu \mathrm{M}$ G15 (a GPER-selective antagonist). Mean $\pm \mathrm{SEM}, \mathrm{n}=6,{ }^{* *} P<0.01,{ }^{* * *} P<0.001$, ${ }^{* * * *} P<0.0001$. (B) Boyden chamber migration assay in HT-29 cells under normoxic and hypoxic conditions. Representative images are shown. Cells were treated with E2, G1, G15, G15+E2 or G15+G1. Mean $\pm \mathrm{SEM}, \mathrm{n}=6,{ }^{*} P<0.01$ E2 and G1 treatment compared to Ct1 (Veh only), $\uparrow P<0.01$ G15+E2 compared to E2 treatment, $₫ P<0.01$ G15+E2 compared to G15 treatment, $\S P<0.01$ G15 $+\mathrm{G} 1$ compared to G1 treatment, ${ }^{* * *} \mathrm{P}<0.0001 \mathrm{G} 15$ compared to $\mathrm{E} 2$ and $\mathrm{G} 1, \uparrow \uparrow \uparrow P<0.001 \mathrm{G} 15+\mathrm{E} 2$ treatment compared to $\mathrm{E} 2$ treatment, $\S \S \S P<0.0001 \mathrm{G} 15+\mathrm{G} 1$ compared to G1 treatment. 

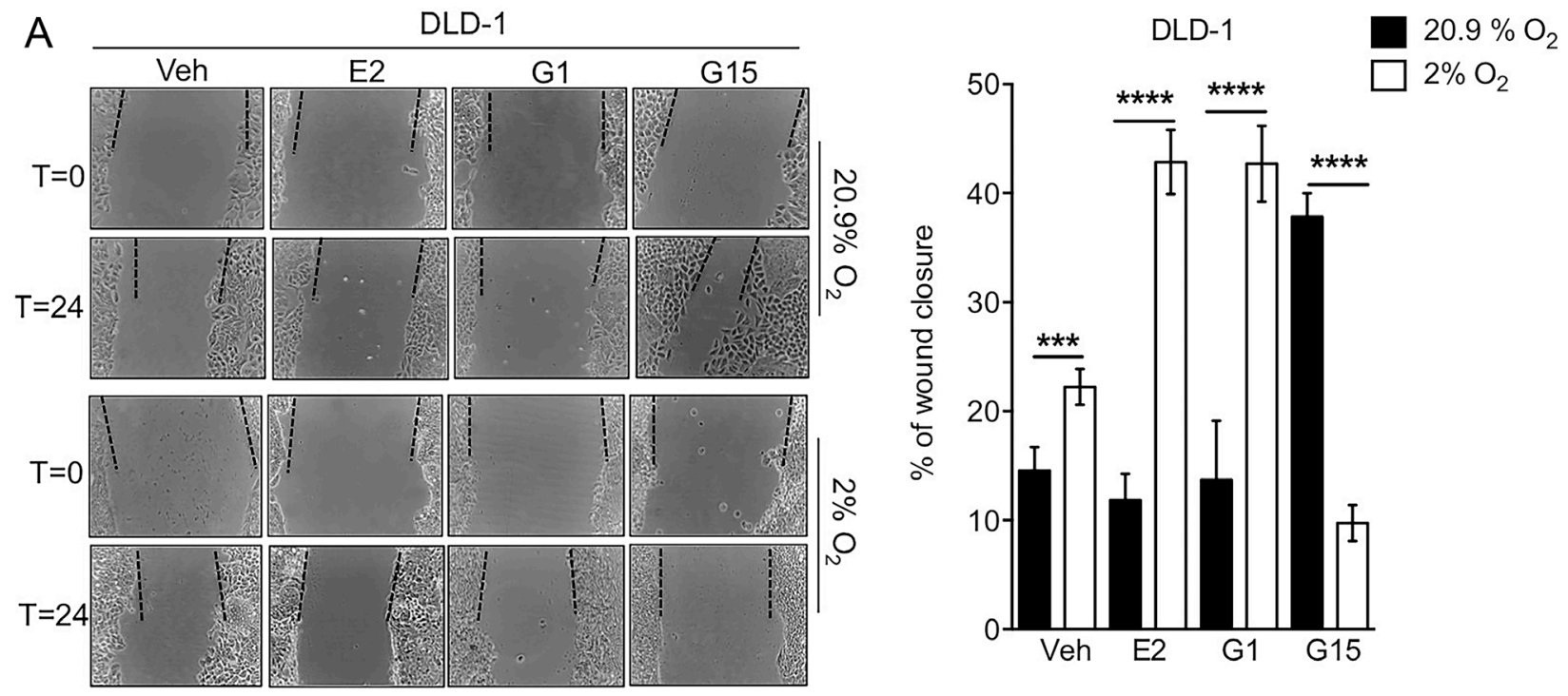

B DLD-1
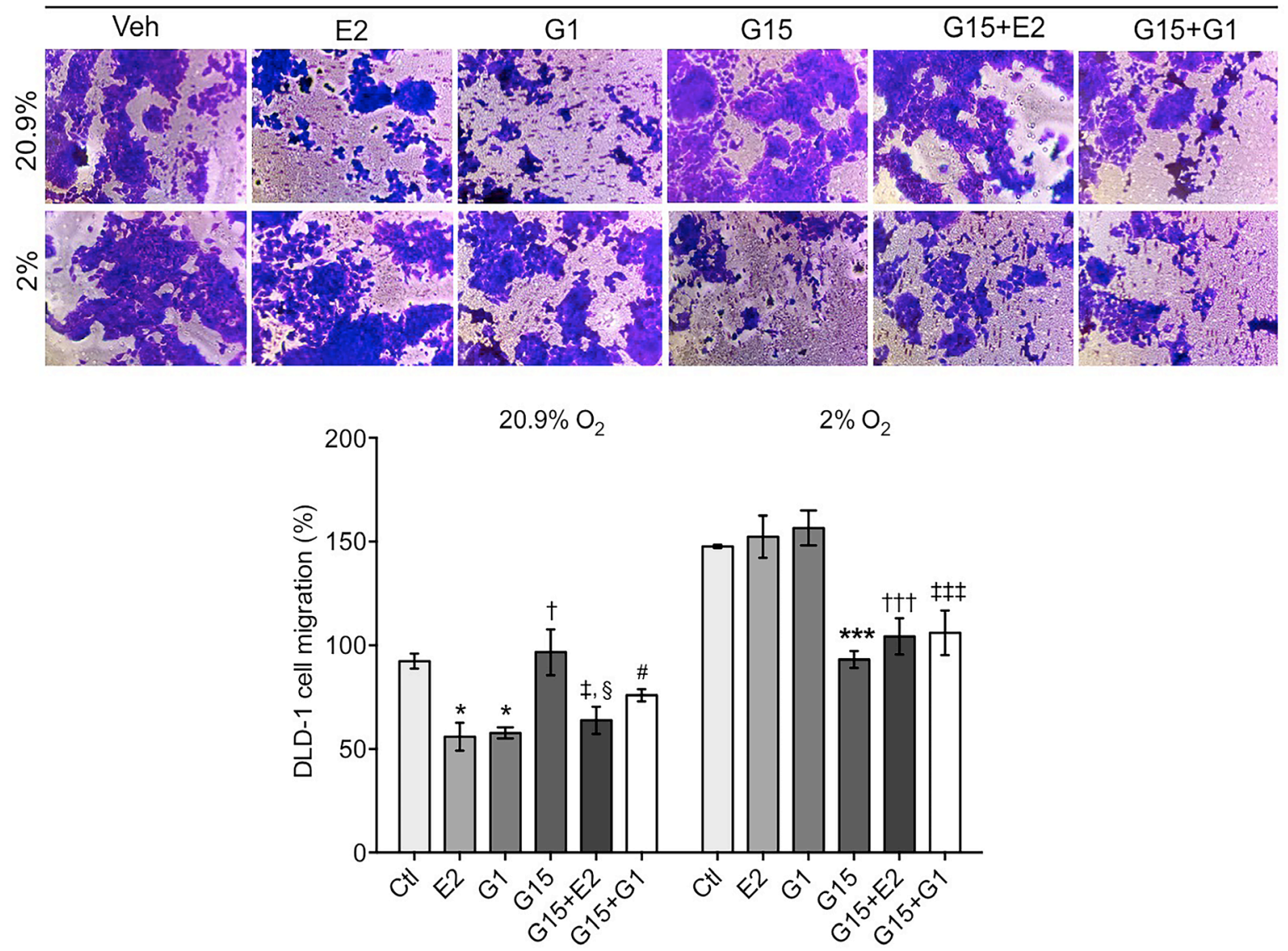

Figure 8: Oxygen-dependent regulation of wound healing and migration by estradiol in DLD-1 cells. (A) Wound healing assay in DLD-1 cells under normoxic $\left(20.9 \% \mathrm{O}_{2}\right)$ and hypoxic $\left(2 \% \mathrm{O}_{2}\right)$ conditions. Representative images are shown of the scratches at time 0 and following 24h. Dashed lines indicate wound margins. Graph shows the \% wound closure under each condition. Cells were treated with 10nM estradiol (E2), 1 $\mu \mathrm{M}$ G1 (a GPER-selective agonist) or $5 \mu \mathrm{M}$ G15 (a GPER-selective antagonist). Mean \pm SEM, $\mathrm{n}=6$, ${ }^{* * *} P<0.001,{ }^{* * * *} P<0.0001$. (B) Boyden chamber migration assay in DLD-1 cells under normoxic and hypoxic conditions. Representative images are shown. Cells were treated with E2, G1, G15, G15+E2 or G15+G1. Mean \pm SEM, $\mathrm{n}=6,{ }^{*} P<0.01$ E2 and G1 treatment compared to $\mathrm{Ctl}$ (Veh only), $\uparrow P<0.01$ G15 compared to G1 and E2 treatment, $\$ P<0.01$ G15+E2 compared to G15 treatment, $\S P<0.01$ G15+E2 compared to $\mathrm{E} 2$ and $\mathrm{G} 1$ treatment, $\# P<0.01 \mathrm{G} 15+\mathrm{G} 1$ compared to $\mathrm{G} 15,{ }^{* * *} \mathrm{P}<0.0001 \mathrm{G} 15$ compared to $\mathrm{E} 2$ and $\mathrm{G} 1, \uparrow \dagger \uparrow P<0.001 \mathrm{G} 15+\mathrm{E} 2$ treatment compared to $\mathrm{E} 2$ or $\mathrm{G} 1$ treatments, $\$+\$ P<0.0001 \mathrm{G} 15+\mathrm{G} 1$ compared to $\mathrm{E} 2$ or $\mathrm{G} 1$ treatments. 
GPER has previously been reported as a target of HIF 1- $\alpha$ in breast cancer cells [32] and here we confirm that hypoxia induces the expression of GPER in CRC cells. Given that ER $\beta$ is frequently lost in the hypoxic microenvironment as CRC malignancy progresses, this up-regulation of GPER is important to maintain estrogenic signaling. Furthermore, we demonstrate that E2 itself enhances GPER expression under both normoxic and hypoxic conditions, enabling an enhanced estrogenic response. It is well established that selective estrogen receptor ligands can produce differential effects by acting on different receptors within the one cell. Here we have demonstrated that in the absence of ER $\alpha$ or ER $\beta$, GPER is essential for transducing both the protective effects (in normoxia) and pro-tumorigenic effects (in hypoxia) of E2. Thus in order to fully understand an estrogenic response it is essential to appreciate not only the estrogen receptor status of the tumor cells but also the hypoxic conditions of the local tumor microenvironment.

$A T M$ was identified as a novel E2-repressed mRNA in HT-29, HCT116 and DLD-1 CRC cells and, interestingly, was also variously repressed under hypoxia in these CRC cell lines. The E2-mediated repression of $A T M$ was found to occur via GPER-mediated signalling. This is in contrast to the ER $\alpha$-mediated repression of ATM found in breast cancer cells [33]. Though not explored in this study, it is conceivable that other mechanisms of E2 action, in addition to activation of GPER, may contribute to the down-regulation of ATM expression. Estrogen increased GPER mRNA and protein expression under both normoxic and hypoxic conditions while E2 had a more potent repressive effect on ATM expression under hypoxic conditions. The regulatory effect of E2 on the expression of GPER may explain some differences in the potency of E2 and G1 to modulate ATM expression. For example, the GPER agonist G1 repressed ATM expression to a lesser extent than E2. However, owing to the undetectable expression of ER $\alpha$ in HT-29 cells, this data clearly highlights that different mechanisms for E2-mediated ATM repression occur in a cell type-specific manner. Since the loss of ATM expression is associated with worse prognosis in CRC patients [22] and ATM expression is reduced in colonic adenomas [34], further repression by combined E2 and low oxygen tension may enhance tumorigenesis.

E2 is frequently considered to play a protective role in CRC. This is evidenced by epidemiological studies in premenopausal women, or postmenopausal women taking hormone replacement therapy (HRT), who are significantly less likely than males to develop CRC [1, 36]. Moreover, a better CRC survival of women compared to men is found especially in the younger age groups [2, 35]. The cellular basis for this protective effect of E2
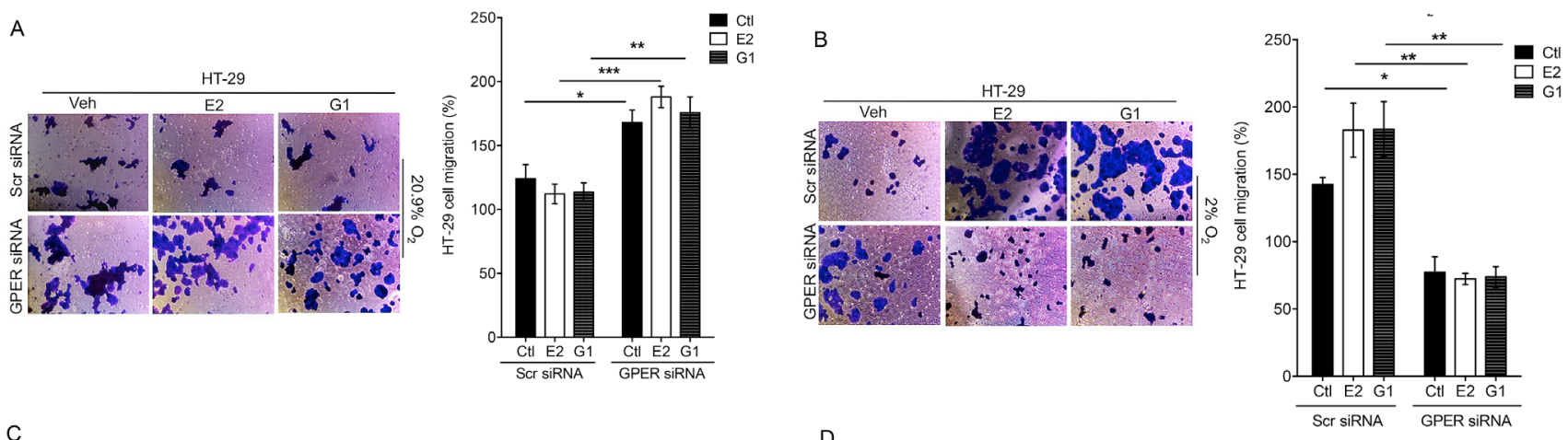

C
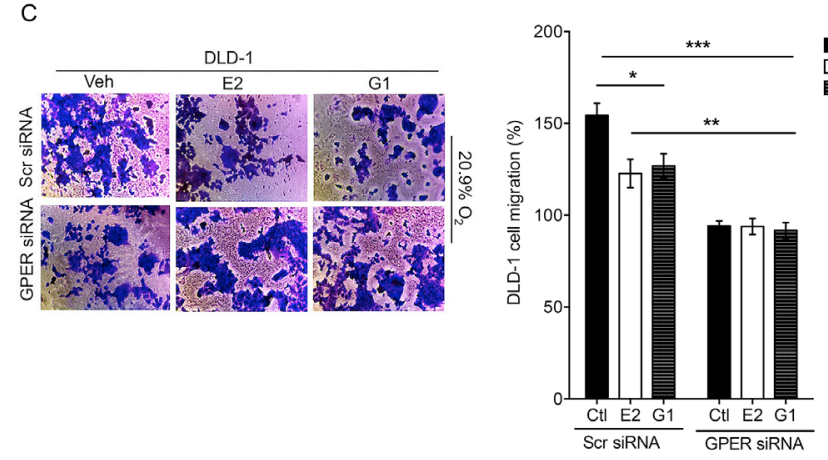

D
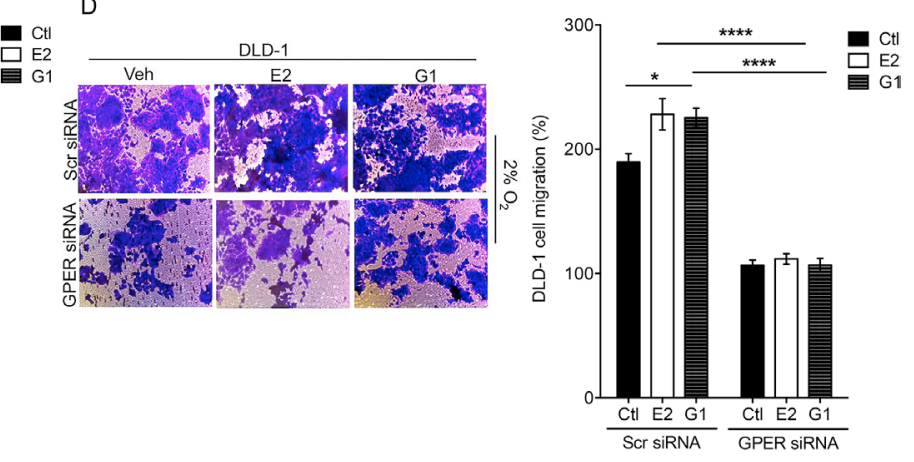

Figure 9: GPER-dependent regulation of migration by estrogen in HT-29 cells. Boyden chamber migration assay in transfected HT-29 and DLD-1 cells under normoxic (A, C) and hypoxic (B, D) conditions. Cells were transfected with control scrambled siRNA (Scr) or GPER-targeting siRNA (GPER siRNA). Cells were treated with ethanol (Veh), 10nM estradiol (E2) or 1 $\mu$ M G1 for $24 \mathrm{~h}$. Graph shows \% cell migration. Mean $\pm \mathrm{SEM}, \mathrm{n}=6,{ }^{*} P<0.05,{ }^{* *} P<0.01,{ }^{* * *} P<0.001,{ }^{* * * *} P<0.0001$. 
A

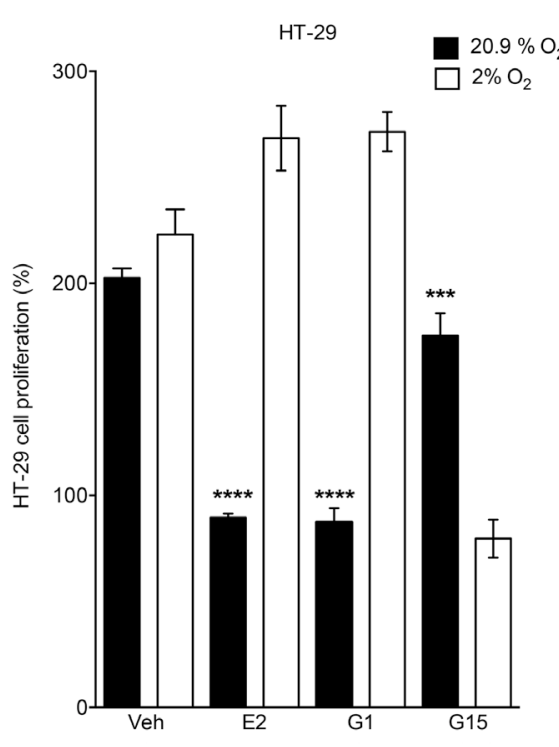

C

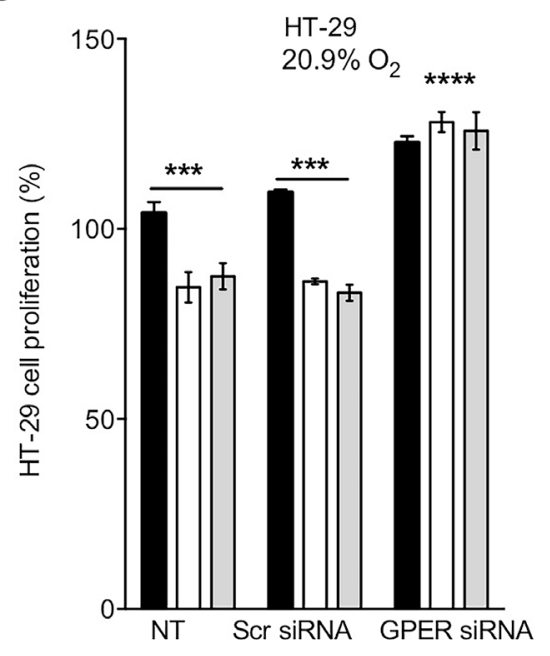

E

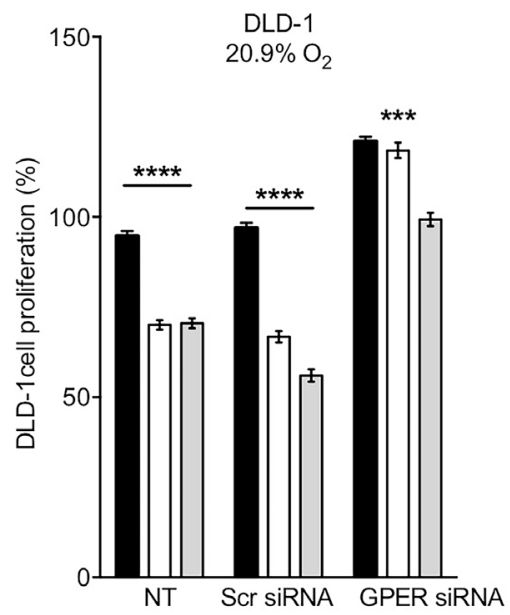

B
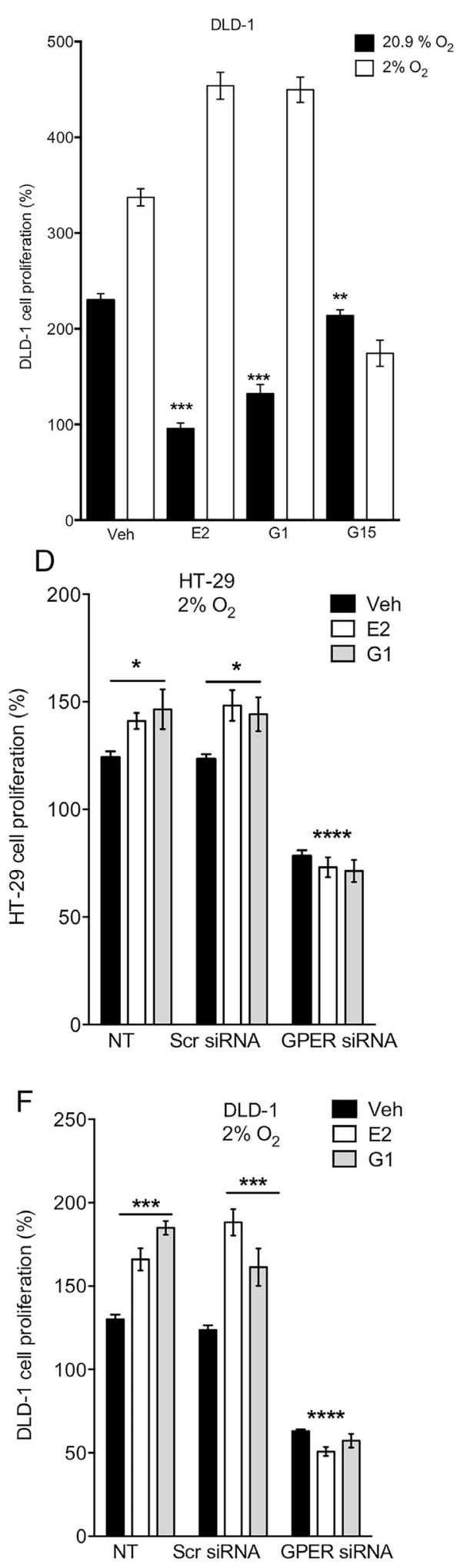

Figure 10: Oxygen- and GPER- dependent regulation of proliferation by estrogen in HT-29 cells. (A, B) Proliferation assay in normoxic and hypoxic HT-29 (A) and DLD-1 (B) cells treated with E2 (10nM), G1 (1 $\mu$ M) and/or G15 (5 $\mu \mathrm{M})$ for 48h. Mean \pm SEM, n=15. ${ }^{* * *} P<0.001,{ }^{* * * * *} P<0.0001$. (C, D) Proliferation assay in normoxic HT-29 (C) and DLD-1 (D) transfected cells treated with Veh, E2 or G1. Cells were transfected with control scrambled or GPER-targeting siRNA. (E, F) Proliferation assay in hypoxic HT-29 (E) and DLD-1 (F) transfected cells treated with Veh, E2 or G1. Cells were transfected with control scrambled (Scr) or GPER-targeting siRNA. Mean \pm SEM, $\mathrm{n}=12,{ }^{*} P<0.01,{ }^{* * *} P<0.001,{ }^{* * * *} P<0.0001$. 
is believed to be through ER $\beta$ and ongoing research is exploring the possibility of utilizing SERMs as a form of treatment in CRC [36]. Our findings indicate that E2 may also have a pro-tumorigenic role in certain hypoxic microenvironments (for example, deep within a tumor), emphasizing the importance of research into GPERspecific ligands in CRC treatment for ER $\beta$ negative patients and in hypoxic tumors.
A

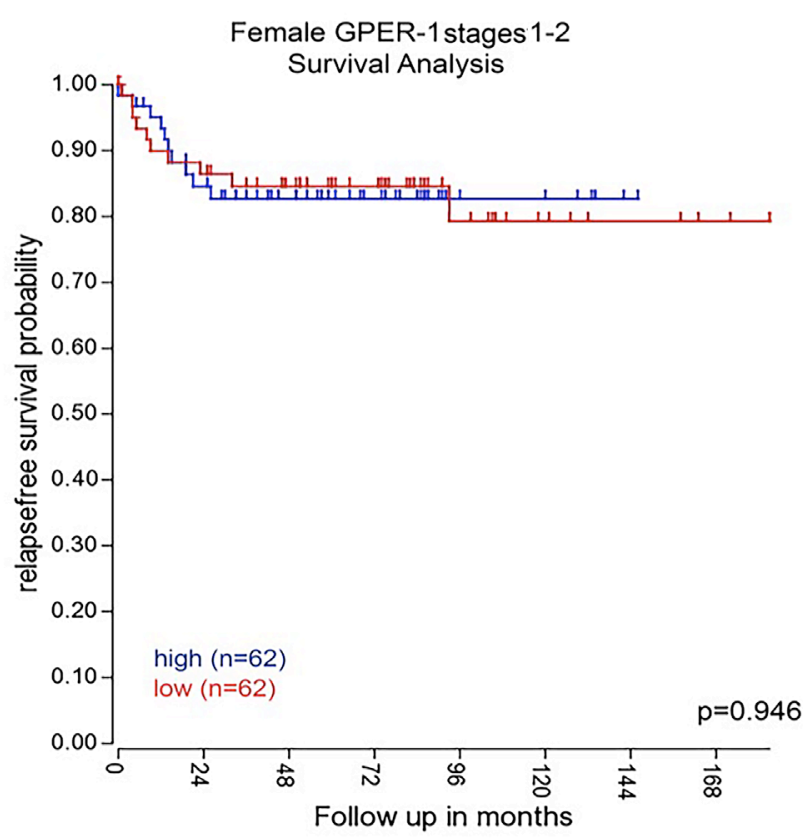

C

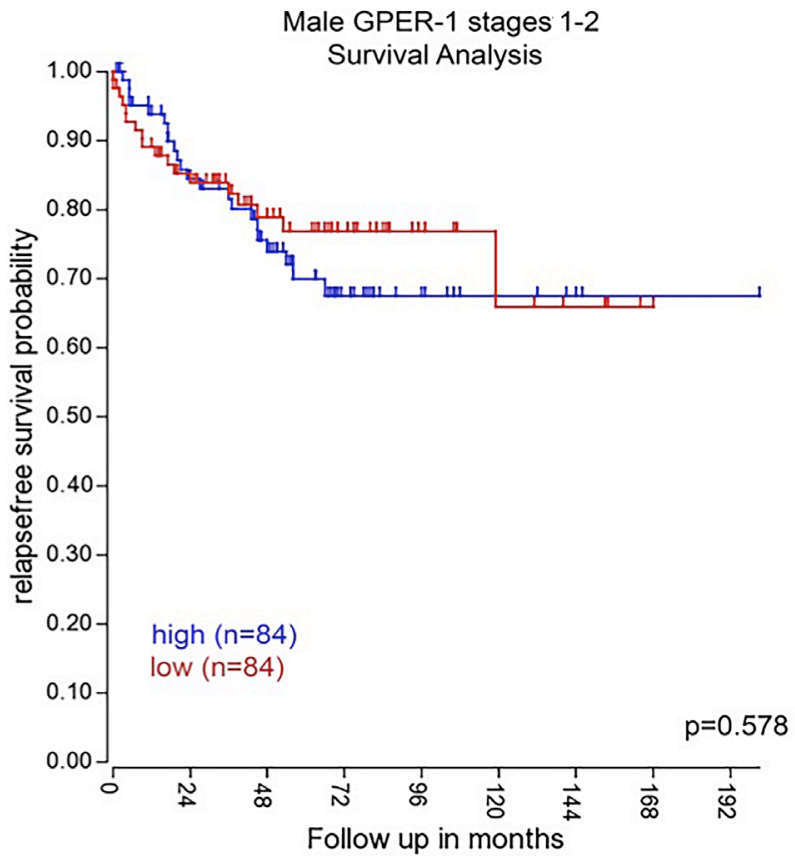

B
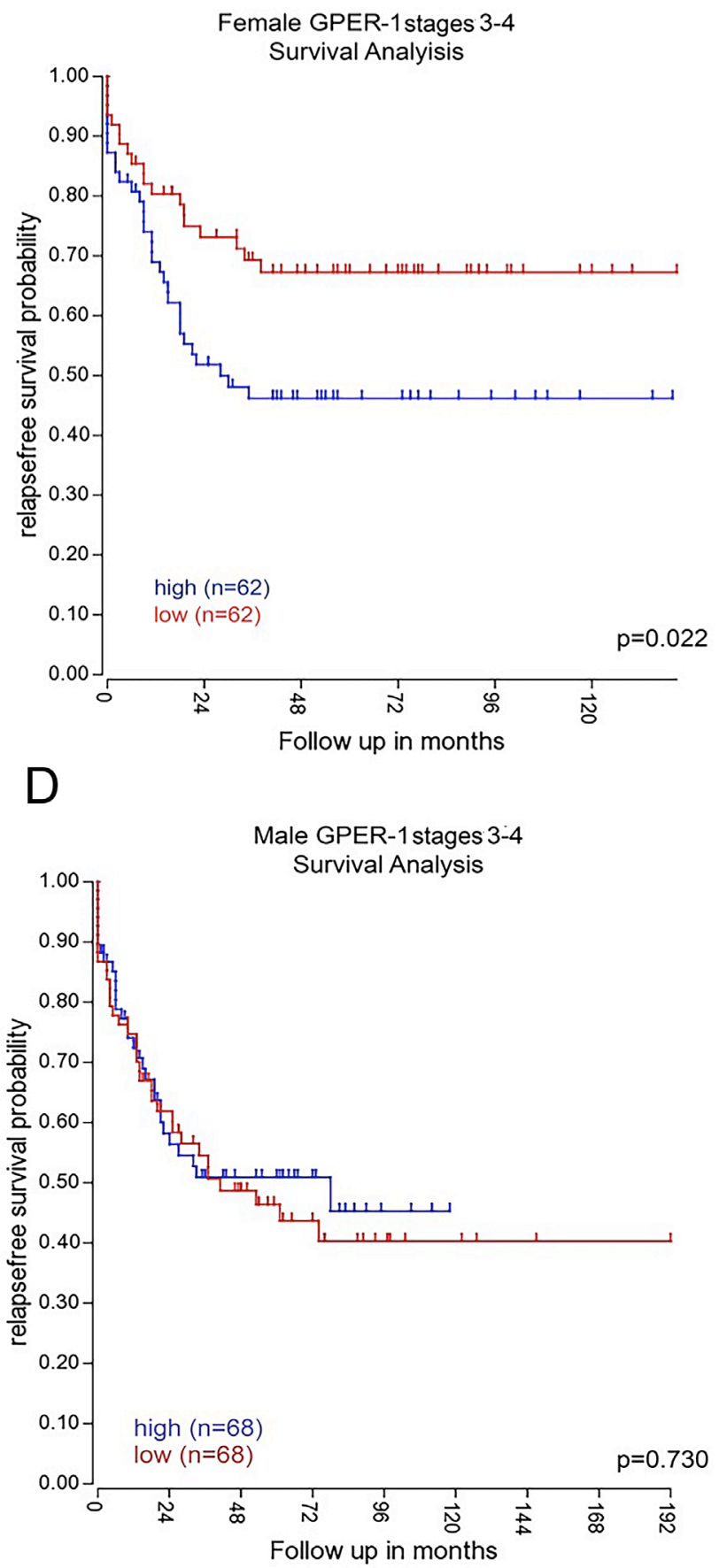

Figure 11: Association of GPER with survival in CRC patients. Kaplan-Meier analysis of relapse-free survival from 566 colon cancer patients. Expression of GPER mRNA using a median cutoff in female patients at stage 1-2 (A) and at stage 3-4 (B) and in male patients stages 1-2 (C) and stages 3-4 (D). Female patients with high GPER had significantly worse survival rates than those with low GPER in the late stages 3-4 $(P=0.022)$. 


\section{MATERIALS AND METHODS}

\section{Cell culture and treatments}

Colon cancer cells (HT-29, HCT116, DLD-1 and HT55) and rectal cancer cells (SW837, C80 and C99) were a kind gift from Professor Ian Tomlinson (Wellcome Trust Centre for Human Genetics, Oxford, UK). We hold an extensive database for cross-checking CRC cell lines including karyotype, APC, KRAS, SMAD4 and TP53 mutation, microsatellite instability status and presence/ absence of 18q. Cells were cultured in Dulbecco's Modified Eagle's Medium (DMEM) (Sigma-Aldrich) supplemented with $10 \%$ foetal bovine serum, $2 \mathrm{mM}$ L-glutamine and $1 \%$ penicillin/streptomycin stock solution (Gibco BRL/Life Technology Inc.) at $37^{\circ} \mathrm{C}, 5 \%$ carbon dioxide and $20.9 \%$ oxygen. For low oxygen tensions, cells were grown in an Invivo2 1000 Hypoxia Workstation (Ruskinn Life Sciences Ltd.) at 1-2\% oxygen (hypoxic) for 24,48 or $72 \mathrm{~h}$. Cell culture media was replaced with serum- and phenol red-free DMEM (Sigma) overnight prior to treatment with E2 (10nM) (Sigma) or ethanol (vehicle) for $24 \mathrm{~h}$. For siRNA transfection experiments, HT-29 cells were incubated $48 \mathrm{~h}$ post transfection under normoxic $(20.9 \%$ oxygen) or low oxygen tension $(1-2 \%$ oxygen) in oxygen Control Glove Box Hypoxic Chamber (Coy Lab. Products) and treated with E2 (10nM), vehicle (EtOH) or phenol red-free DMEM for $24 \mathrm{~h}$.

\section{Reverse transcription and real-time quantitative PCR}

Total RNA was extracted using Total RNA Purification $\mathrm{Kit}^{\circledR}$ (Norgen, Biotek Corp.) Reverse transcription was performed using the High Capacity RNA-to-cDNA ${ }^{\mathrm{TM}}$ Kit (Applied Biosystems ${ }^{\circledR}$ ). The TaqMan $^{\circledR}$ assays used were: HIF1A: Hs00936366_m1; VEGFA: Hs99999070_m1; GPER: Hs01922715_s1; ATM: Hs01112307_m1. Real-time quantitative PCR analyses were performed in triplicate on a 7900 HT Fast Realtime System. Peptidylprolyl isomerase B (cyclophilin B) $(P P I B)(\mathrm{Hs} 00168719 \mathrm{ml})$ [37] or 18S rRNA (Hs99999901_s1) were used for normalization. A relative fold change in expression of the target gene transcript was determined using the comparative cycle threshold method $\left(2^{-\Delta \Delta C T}\right)[38]$. A Ct value of 35 represents single molecule template detection, and so where $\mathrm{Ct}$ values are $\geq 35$ the target gene is considered not expressed [39].

\section{Western blot analysis}

Protein cell lysates were prepared by washing cells in phosphate-buffered saline (PBS) twice and solubilizing with RIPA buffer. Protein concentration in the supernatant was determined using the DC ${ }^{\text {TM }}$ Protein Assay Kit
(Bio-Rad Laboratories Inc.). Proteins were separated on $6 \%$ (ATM) and 10\% (GPER, VEGFA, HIF1- $\alpha$, $\mathrm{N}$-cadherin, E-cadherin) polyacrylamide gels, blotted onto PVDF membrane and probed with well-characterised antibodies to hGPER (R\&D Systems, AF5534, 1:1500 or Abcam Anti-G-protein coupled receptor 30 antibody C-terminal, ab154069, 1:1500), HIF1- $\alpha$ (BD Transduction Laboratories, 610958, 1:1500), VEGFA (ABS82, Millipore, 1:1500), ATM (Cat. A300-299A, Bethyl, 1:1000), N-Cadherin (sc-59987, Santa Cruz), E-Cadherin (sc-21791, Santa Cruz, 1:1000), GAPDH (A5316, Santa Cruz, 1:5000) and $\beta$-actin (Sigma, A5316, 1:10000). Signal was detected using the Amersham ${ }^{\mathrm{TM}}$ ECL $^{\mathrm{TM}}$ Prime Western Blotting Detection Reagent (GE Healthcare). Image was developed using Amersham Imager 600 and processed using Image J software [40]. As detailed in the data sheets for the antibodies used, GPER is routinely seen by Western blot as a clear band at approximately $55 \mathrm{kDa}$ (https://www.rndsystems.com/products/humangper-antibody_af5534\#ds_image_0; http://www.abcam. com/g-protein-coupled-receptor-30-antibody-c-terminalab154069.html).

\section{Cell migration analysis}

HT-29 and DLD-1 cell migration was measured by the wound closure rate of an injured confluent cell monolayer seeded at equal densities in 6-well plates. The monolayer, in phenol red-free DMEM containing 10\% charcoal-stripped serum (steroid-deprived) was scratched (central vertical line) using a $10 \mu \mathrm{l}$ pipette tip and images were immediately acquired (5 pictures/well, $0 \mathrm{~h}$ ) using a Samsung I310W camera. The medium was replaced with, untreated or treated with E2 $(10 \mathrm{nM})$ or G1 $(1 \mu \mathrm{M})$ or G15 $(5 \mu \mathrm{M})$ or vehicle (ethanol $1000 \mathrm{x}$ ) and incubated at the required oxygen tension for $24 \mathrm{~h}$. After incubation, images corresponding to locations at $24 \mathrm{~h}$ were acquired. Images were obtained from 5 pictures per well using a total of 6 wells per condition performed in triplicate. The fractional closure was measured using Image J software.

\section{Cell proliferation analysis}

HT-29 and DLD-1 wild type and GPER-1 knock down cells were seeded in 96-well plates $\left(5 \times 10^{3}\right.$ HT-29 cells/well and $1 \times 10^{3}$ DLD-1 cells/well) and incubated overnight at $37^{\circ} \mathrm{C}$. Cells were then either untreated or treated with E2, G1, G15 or vehicle in phenol red-free serum-free medium and incubated at $20.9 \%$ or $2 \%$ oxygen for $48 \mathrm{~h}$. Cell assays were performed using the CellTitre 96 ${ }^{\circledR}$ Aqueous One Solution Cell Proliferation Assay (Promega Corporation). Values were normalized to the vehicle-treated normoxic in the case of WT experiments or vehicle-treated normoxic non-transfected control in the case of GPER-knockdown cells at 48h. 


\section{Boyden chamber assay}

HT-29 and DLD- 1 cells $\left(1.25 \times 10^{5}\right)$ were allowed to migrate for $48 \mathrm{~h}$ through $8 \mu \mathrm{m}$ pore cell culture inserts (24 well Millicell, Millipore). Non-migratory cells were carefully removed by Q-tip from the surface of the inserts. Migratory cells were stained with $0.1 \%$ crystal violet (Crystal violet $1 \%$ aqueous solution, V5265, Sigma). Three independent fields of migratory cells per well were photographed under phase contrast microscopy. To quantify invasive cells, acetic acid 30\% was used to remove the crystal violet and then absorbance was measured at $490 \mathrm{~nm}$. Each condition of migration assay was repeated on 3 independent occasions.

\section{Transfection with GPER1 siRNA}

HT- 29 cells and DLD- 1 were seeded in $5 \mathrm{ml}$ phenol red-free DMEM (Sigma) growth medium into $25 \mathrm{~cm}^{2}$ culture flasks and grown to $80 \%$ confluence. The cells were washed in PBS twice, trypsinized, spun down at $1100 \mathrm{~g}$ and re-suspended in culture medium. Silencer ${ }^{\mathbb{R}}$ Select Negative Control \#1 siRNA (5nmol, Cat.\#AM4635, Ambion ${ }^{\circledR}$ ), GPER-1 Silencer selected RNA (5 nmol, Cat.\# 4390824, Ambion ${ }^{\circledR}$ ) were introduced into the cells by reverse transfection using the siPORT $^{\mathrm{TM}}$ NeoFX ${ }^{\mathrm{TM}}$ transfection reagent $\left(\right.$ Ambion $\left.^{\circledR}\right)$. In brief, the siRNA was dissolved in RNase-free water at a concentration of $50 \mu \mathrm{M}$ and then $100 \mathrm{nM}$ of each siRNA stock solution was diluted in $100 \mu 1$ of OptiMEM medium (Sigma Aldrich). Separately, $5 \mu 1$ of siPORT ${ }^{\mathrm{TM}} \mathrm{NeoFX}^{\mathrm{TM}}$ transfection reagent was dissolved in $100 \mu$ of OptiMEM medium. Equal volumes of the diluted siRNA and transfection reagent were mixed and incubated at room temperature for $10 \mathrm{~min}$. The cells were prepared in $1 \mathrm{ml}$ of OptiMEM medium at $3 \times 10^{4}$ density in six-well plates for mRNA and protein analysis. The mixture of siRNA and transfection reagent was added to each well and the transfection was started. After $6 \mathrm{~h}, 1 \mathrm{ml}$ of a phenol red-free DMEM (Sigma) containing $10 \%$ of FBS and antibiotics was added to the transfected cells. After further $18 \mathrm{~h}$, the remaining siRNA was aspirated and cells were grown in serum-free and phenol red-free DMEM (Sigma) for 24h.

\section{Kaplan-Meier analysis}

Kaplan-Meier analysis of relapse free patient survival was carried out in 566 primary colon cancer tumors using the R2 bioinformatics web tool (R2: Genomics analysis and visualization platform http:// r2.amc.nl) on the previously published data set GSE39582 [41] Substratification of tumors based on patient gender and tumor stage at diagnosis was also carried out. Median gene expression was used to stratify patients into high or low expression for the gene being examined. P-values were calculated based on a log rank test.

\section{Statistical analyses}

All values are reported as means \pm SEM and compared using a Student's $t$-test. To compare multiple groups, a one-way analysis of variance (ANOVA) multiple comparisons test was applied. Kruskal-Wallis nonparametric test was applied to compare significance between two or more groups, as appropriate. Differences between the means were considered statistically significant when $\mathrm{p} \leq 0.05$.

\section{CONCLUSION}

This study highlights the influence of GPER status and the cellular hypoxic microenvironment on E2 action in $\mathrm{CRC}$ malignancy. E2 treatment synergises with hypoxia by repressing ATM expression via GPER, and combined with the activation of HIF1- $\alpha$ and VEGFA, potentiates the hypoxia-induced cell migration and proliferation. It appears that the role of $\mathrm{E} 2$ in CRC progression is complicated by the relative expression of the different estrogen-ligand receptors and GPER under varying ambient oxygen tension and is not simply, as previously suggested, to be a unique protective effect through ER $\beta$ activation. The potential exacerbating effects of E2 in $\mathrm{CRC}$ under hypoxic conditions and its signal transduction via GPER require further research. The sexual dimorphism of E2 actions on CRC cell biology transduced through differential ER/GPER expression under varying oxygen tensions may resolve the controversies of epidemiological studies confounded by age, gender, hypoxia, tumor stage and HRT in CRC patients.

\section{Author contributions}

VB performed experiments, analysed and interpreted the data, contributed to writing and revision of the manuscript.

ÁMN performed experiments, analysed and interpreted the data, contributed to writing of the manuscript.

AN provided samples for initial mRNA screen to inform project concept, contributed to experimental design and supervision, revision of the manuscript.

$\mathrm{HH}$ performed the Kaplan Meier analysis and revision of the manuscript.

AP provided samples for initial mRNA screen to inform project concept and experimental design, revision of the manuscript.

RP contributed to experimental design, data interpretation, revision of the manuscript.

JMB contributed to interpretation of experiments, writing and revision of the manuscript.

WT conceived, designed and interpreted the experiments, writing and revision of the manuscript. 
AS conceived, designed and interpreted the experiments, writing and revision of the manuscript.

$\mathrm{BJH}$ conceived, designed and interpreted the experiments, writing and revision of the manuscript.

All authors read and approved the final manuscript.

\section{ACKNOWLEDGMENTS}

We thank the Cancer Metabolism Group (Nuffield Department of Medicine, Oxford University, Oxford, UK), in particular Dr Patrick Pollard, Dr Julia Adam and Dr Norma Masson for the use of hypoxia chambers, HIF1A antibody and their technical advice. We thank Prof Cormac Taylor for providing access to hypoxia chambers at University College Dublin.

\section{CONFLICTS OF INTEREST} interests.

All authors declare the absence of known competing

\section{FUNDING}

ÁMN was supported by the Health Research Board in Ireland (PHD/2007/11 to BJH) and Science Foundation Ireland (12/TIDA/I2372 to WT). AN and AP held Constance Travis Charitable Trust studentships. The funding bodies had no role in study design, the collection, analysis or interpretation of data, in the writing of the manuscript or in the decision to submit the manuscript for publication.

\section{REFERENCES}

1. Ferlay J, Shin HR, Bray F, Forman D, Mathers C, Parkin DM. Estimates of worldwide burden of cancer in 2008: GLOBOCAN 2008. Int J Cancer. 2010; 127:2893-2917.

2. Hendifar A, Yang D, Lenz F, Lurje G, Pohl A, Lenz C, Ning Y, Zhang W, Lenz H. Gender Disparities in Metastatic Colorectal Cancer Survival. Clin Cancer Res. 2009; 15:6391-6397.

3. Koo J, Jalaludin B, Wong S, Kneebone A, Connor S, Leong R. Improved survival in young women with colorectal cancer. Am J Gastroenterol. 2008; 103:1488-1495.

4. Delellis Henderson K, Duan L, Sullivan-Halley J, Ma H, Clarke C, Neuhausen S, Templeman C, Bernstein L. Menopausal Hormone Therapy Use and Risk of Invasive Colon Cancer The California Teachers Study. Am J Epidemiol. 2010; 171:415-425.

5. Manson J, Chlebowski R, Stefanick M, Aragaki A, Rossouw J, Prentice R, Anderson G, Howard B, Thomson C, LaCroix A, Wactawski-Wende J, Jackson RD, Limacher M, et al. Menopausal hormone therapy and health outcomes during the intervention and extended poststopping phases of the
Women's Health Initiative randomized trials. JAMA. 2013; 310:1353-1368.

6. The Women's Health Initiative Study Group. Design of the Women's Health Initiative clinical trial and observational study. Control Clin Trials. 1998; 19:61-109.

7. Calle E, Miracle-McMahill H, Thun M, Heath CJ. Estrogen replacement therapy and risk of fatal colon cancer in a prospective cohort of postmenopausal women. J Natl Cancer Inst. 1995; 87:517-523.

8. Konstantinopoulos PA, Kominea A, Vandoros G, Sykiotis GP, Andricopoulos P, Varakis I, Sotiropoulou-Bonikou G, Papavassiliou AG. Oestrogen receptor beta (ER $\beta$ ) is abundantly expressed in normal colonic mucosa, but declines in colon adenocarcinoma paralleling the tumour's dedifferentiation. Eur J Cancer. 2003; 39:1251-1258.

9. Rudolph A, Toth C, Hoffmeister M, Roth W, Herpel E, Jansen L, Marx A, Brenner H, Chang-Claude J. Expression of oestrogen receptor beta and prognosis of colorectal cancer. Br J Cancer. 2012; 107:831-839.

10. Edvardsson K, Nguyen-Vu T, Kalasekar SM, Pontén F, Gustafsson J, Williams C. Estrogen receptor beta expression induces changes in the microRNA pool in human colon cancer cells. Carcinogenesis. 2013; 34:1431-1441.

11. Cordera F, Jordan VC. Steroid Receptors and Their Role in the Biology and Control of Breast Cancer Growth. Semin Oncol. 2006; 33:631-641.

12. Harris AL. Hypoxia--a key regulatory factor in tumour growth. Nat Rev Cancer. 2002; 2:38-47.

13. Rasheed S, Harris A, Tekkis P, Turley H, Silver A, McDonald P, Talbot I, Glynne-Jones R, Northover J, Guenther T. Hypoxia-inducible factor-1alpha and -2alpha are expressed in most rectal cancers but only hypoxiainducible factor-1alpha is associated with prognosis. $\mathrm{Br} \mathrm{J}$ Cancer. 2009; 100:1666-1673.

14. Cao D, Hou M, Guan Y, Jiang M, Yang Y, Gou H. Expression of HIF-1alpha and VEGF in colorectal cancer: association with clinical outcomes and prognostic implications. BMC Cancer. 2009; 9:432.

15. Bencokova Z, Kaufmann M, Pires I, Lecane P, Giaccia A, Hammond E. ATM activation and signaling under hypoxic conditions. Mol Cell Biol. 2009; 29:526-537.

16. Kumareswaran R, Ludkovski O, Meng A, Sykes J, Pintilie M, Bristow RG. Chronic hypoxia compromises repair of DNA double-strand breaks to drive genetic instability. J Cell Sci. 2012; 125:189-199.

17. Beggs A, Domingo E, McGregor M, Presz M, Johnstone E, Midgley R, Kerr D, Oukrif D, Novelli M, Abulafi M, Hodgson SV, Fadhil W, Ilyas M, Tomlinson IP. Loss of expression of the double strand break repair protein ATM is associated with worse prognosis in colorectal cancer and loss of $\mathrm{Ku} 70$ expression is associated with CIN. Oncotarget. 2012; 3:1348-1355. https://doi.org/10.18632/ oncotarget.694. 
18. Ousset M, Bouquet F, Fallone F, Biard D, Dray C, Valet P, Salles B, Muller C. Loss of ATM positively regulates the expression of hypoxia inducible factor 1 (HIF-1) through oxidative stress: Role in the physiopathology of the disease. Cell Cycle. 2010; 9:2814-2822.

19. El-Khatib M, Geara F, Haddadin M, Gali-Muhtasib H. Cell death by the quinoxaline dioxide DCQ in human colon cancer cells is enhanced under hypoxia and is independent of p53 and p21. Radiat Oncol. 2010; 5.

20. George A, Rajoria S, Suriano R, Mittleman A, Tiwari R. Hypoxia and estrogen are functionally equivalent in breast cancer-endothelial cell interdependence. Mol Cancer. 2012; 11:80.

21. De Francesco EM, Pellegrino M, Santolla MF, Lappano R, Ricchi, E, Abonante S, Maggiolini M. GPER mediates activation of HIF $1 \alpha /$ VEGF signaling by estrogens. Cancer Res. 2014; 74:4053-64. https://doi.org/10.1158/0008-5472.

22. Sengupta K, Banerjee S, Saxena N, Banerjee SK. Estradiolinduced vascular endothelial growth factor-A expression in breast tumor cells is biphasic and regulated by estrogen receptor-alpha dependent pathway. Int J Oncol. 2003; 22:609-14.

23. Guthrie J, Seah C, Brown S, Tang P, Jamieson F, Drews S. Use of Bordetella pertussis BP3385 to establish a cutoff value for an IS481-targeted real-time PCR assay. J Clin Microbiol. 2008; 46:3798-3799.

24. Wu MH, Lu CW, Chang FM, Tsai SJ. Estrogen receptor expression affected by hypoxia inducible factor- $1 \alpha$ in stromal cells from patients with endometriosis. Taiwan J Obstet Gynecol. 2012; 51:50-54.

25. Ryu K, Park C, Lee Y. Hypoxia-inducible factor 1 alpha represses the transcription of the estrogen receptor alpha gene in human breast cancer cells. Biochem Biophys Res Commun. 2011; 407:831-836.

26. Benita Y, Kikuchi H, Smith A, Zhang M, Chung D, Xavier R. An integrative genomics approach identified Hypoxia Inducible Factor-1 (HIF-1)-target genes that form the core response to hypoxia. Nucleic Acids Res. 2009; 37:4587-4602.

27. Christensen J, El-Gebali S, Natoli M, Sengstag T, Delorenzi M, Bentz S, Bouzourene H, Rumbo M, Felsani A, Siissalo $\mathrm{S}$, Hirvonen J, Vila MR, Saletti P, et al. Defining new criteria for selection of cell-based intestinal models using publiclyavailable databases. BMC Genomics. 2012; 13:274.

28. Rapetti-Mauss R, Bustos V, Thomas W, McBryan J, Harvey H, Lajczak N, Madden SF, Pellissier B, Borgese F, Soriani O, Harvey BJ. Bidirectional KCNQ1: $\beta$-catenin interaction drives colorectal cancer cell differentiation. Proc Natl Acad Sci U S A. 2017; 114:4159-4164.

29. Rigiracciolo DC, Scarpelli A, Lappano R, Pisano A, Santolla MF, De Marco P, Cirillo F, Cappello AR, Dolce V, Belfiore A, Maggiolini M, De Francesco E. Copper activates HIF-1 $\alpha /$ GPER/VEGF signalling in cancer cells. Oncotarget. 2015; 6:34158-77. https://doi.org/10.18632/ oncotarget.5779.

30. De Francesco E, Lappano R, Francesca M, Marsico S, Caruso A, Maggiolini M. HIF-1alpha/GPER signaling mediates the expression of VEGF induced by hypoxia in breast cancer associated fibroblasts (CAFs). Breast Cancer Res. 2013; 15:R64.

31. Iyer NV, Kotch LE, Agani F, Leung SW, Laughner E, Wenger RH, Gassmann M, Gearhart JD, Lawler AM, Yu AY. Cellular and developmental control of O2 homeostasis by hypoxia inducible factor $1 \alpha$. Genes \& Dev. 1998; 12:149-162.

32. Recchia A, De Francesco E, VIivacqua A, Sisci D, Panno $\mathrm{M}$, Andó S, Maggiolini M. The G protein-coupled receptor 30 is up-regulated by hypoxia-inducible factor-1 alpha (HIF-1alpha) in breast cancer cells and cardiomyocytes. J Biol Chem. 2011; 286:10773-10782.

33. Guo X, Yang C, Qian X, Lei T, Li Y, Shen H, Fu L, $\mathrm{Xu}$ B. Estrogen receptor $\alpha$ regulates ATM Expression through miRNAs in breast cancer. Clin Cancer Res. 2013; 19:4994-5002.

34. Bai A, Tong J, To KF, Chan M, Man E, Lo K, Lee J, Sung J, Leung W. Promoter hypermethylation of tumor-related genes in the progression of colorectal neoplasia. Int $\mathrm{J}$ Cancer. 2004; 112:846-853.

35. Barzi A, Lenz AM, Labonte MJ, Lenz HJ. Molecular pathways: Estrogen pathway in colorectal cancer. Clin Cancer Res. 2013; 19:5842-8.

36. Foster PA. Oestrogen and colorectal cancer: mechanisms and controversies. Int J Colorectal Dis. 2013; 28:737-49.

37. Pachot A, Blond J, Mougin B, Miossec P. Peptidylpropyl isomerase B (PPIB): a suitable reference gene for mRNA quantification in peripheral whole blood. J Biotechnol. 2004; 114:121-124.

38. Livak K, Schmittgen T. Analysis of relative gene expression data using real-time quantitative PCR and the 2(-Delta Delta C(T)) Method. Methods. 2001; 25:402-408.

39. Guthrie J, Seah C, Brown S, Tang P, Jamieson F, Drews S. Use of Bordetella pertussis BP3385 to establish a cutoff value for an IS481-targeted real-time PCR assay. J Clin Microbiol. 2008; 46:3798-3799.

40. Schneider C, Rasband W, Eliceiri K. NIH Image to ImageJ: 25 years of image analysis. Nature Methods. 2012; 9:671-675.

41. Marisa L, de Reyniès A, Duval A, Selves J, Gaub MP, Vescovo L, Etienne-Grimaldi MC, Schiappa R, Guenot D, Ayadi M, Kirzin S, Chazal M, Fléjou JF, et al. Gene expression classification of colon cancer into molecular subtypes: characterization, validation, and prognostic value. PLoS Med. 2013; 10:e1001453. 